\title{
Chronic obstructive pulmonary disease - diagnosis and management of stable disease; a personalized approach to care, using the treatable traits concept based on clinical phenotypes. Position paper of the Czech Pneumological and Phthisiological Society
}

\author{
Jaromir Zatloukal ${ }^{a}$, Kristian Brat ${ }^{b, c}$, Katerina Neumannova ${ }^{d}$, Eva Volakova ${ }^{a}$, Karel Hejduk ${ }^{\text {e,f }}$, Eva Kocova ${ }^{g}$, Ondrej Kudela ${ }^{\mathrm{h}}$, \\ Michal Kopecky ${ }^{\mathrm{h}}$, Marek Plutinsky ${ }^{\mathrm{b},}$, Vladimir Koblizek ${ }^{\mathrm{h}}$
}

This position paper has been drafted by experts from the Czech national board of diseases with bronchial obstruction, of the Czech Pneumological and Phthisiological Society. The statements and recommendations are based on both the results of randomized controlled trials and data from cross-sectional and prospective real-life studies to ensure they are as close as possible to the context of daily clinical practice and the current health care system of the Czech Republic. Chronic Obstructive Pulmonary Disease (COPD) is a preventable and treatable heterogeneous syndrome with a number of pulmonary and extrapulmonary clinical features and concomitant chronic diseases. The disease is associated with significant mortality, morbidity and reduced quality of life.

The main characteristics include persistent respiratory symptoms and only partially reversible airflow obstruction developing due to an abnormal inflammatory response of the lungs to noxious particles and gases. Oxidative stress, protease-antiprotease imbalance and increased numbers of pro-inflammatory cells (mainly neutrophils) are the main drivers of primarily non-infectious inflammation in COPD. Besides smoking, household air pollution, occupational exposure, low birth weight, frequent respiratory infections during childhood and also genetic factors are important risk factors of COPD development. Progressive airflow limitation and airway remodelling leads to air trapping, static and dynamic hyperinflation, gas exchange abnormalities and decreased exercise capacity. Various features of the disease are expressed unequally in individual patients, resulting in various types of disease presentation, emerging as the "clinical phenotypes" (for specific clinical characteristics) and "treatable traits" (for treatable characteristics) concept. The estimated prevalence of COPD in Czechia is around $6.7 \%$ with 3,200-3,500 deaths reported annually.

The elementary requirements for diagnosis of COPD are spirometric confirmation of post-bronchodilator airflow obstruction (post-BD FEV ${ }_{1} / \mathrm{NCmax}<70 \%$ ) and respiratory symptoms assessement (dyspnoea, exercise limitation, cough and/or sputum production. In order to establish definite COPD diagnosis, a five-step evaluation should be performed, including: 1 / inhalation risk assessment, 2 / symptoms evaluation, 3 / lung function tests, 4 / laboratory tests and 5/ imaging. At the same time, all alternative diagnoses should be excluded. For disease classification, this position paper uses both GOLD stages (1 to 4), GOLD groups (A to D) and evaluation of clinical phenotype(s). Prognosis assessment should be done in each patient. For this purpose, we recommend the use of the BODE or the CADOT index.

Six elementary clinical phenotypes are recognized, including chronic bronchitis, frequent exacerbator, emphysematous, asthma/COPD overlap (ACO), bronchiectases with COPD overlap (BCO) and pulmonary cachexia. In our concept, all of these clinical phenotypes are also considered independent treatable traits. For each treatable trait, specific pharmacological and non-pharmacological therapies are defined in this document. The coincidence of two or more clinical phenotypes (i.e., treatable traits) may occur in a single individual, giving the opportunity of fully individualized, phenotype-specific treatment.

Treatment of COPD should reflect the complexity and heterogeneity of the disease and be tailored to individual patients. Major goals of COPD treatment are symptom reduction and decreased exacerbation risk. Treatment strategy is divided into five strata: risk elimination, basic treatment, phenotype-specific treatment, treatment of respiratory failure and palliative care, and treatment of comorbidities.

Risk elimination includes interventions against tobacco smoking and environmental/occupational exposures. Basic treatment is based on bronchodilator therapy, pulmonary rehabilitation, vaccination, care for appropriate nutrition, inhalation training, education and psychosocial support. Adequate phenotype-specific treatment varies phenotype by phenotype, including more than ten different pharmacological and non-pharmacological strategies. If more than one clinical phenotype is present, treatment strategy should follow the expression of each phenotypic label separately. In such patients, multicomponental therapeutic regimens are needed, resulting in fully individualized care.

In the future, stronger measures against smoking, improvements in occupational and environmental health, early diagnosis strategies, as well as biomarker identification for patients responsive to specific treatments are warranted. New classes of treatment (inhaled PDE3/4 inhibitors, single molecule dual bronchodilators, anti-inflammatory drugs, gene editing molecules or new bronchoscopic procedures) are expected to enter the clinical practice in a very few years.

Key words: COPD; position paper; clinical phenotypes; treatable traits; bronchodilators; individualized care; personalized medicine 
Received: October 13, 2020; Revised: November 15, 2020; Accepted: November 20, 2020; Available online: December 14, 2020 https://doi.org/10.5507/bp.2020.056

(c) 2020 The Authors; https://creativecommons.org/licenses/by/4.0/

${ }^{a}$ Department of Respiratory Diseases and Tuberculosis, University Hospital Olomouc and Faculty of Medicine and Dentistry, Palacky University Olomouc, Czech Republic

${ }^{b}$ Department of Respiratory Diseases, University Hospital Brno, Czech Republic

'Faculty of Medicine, Masaryk University, Brno, Czech Republic

${ }^{d}$ Department of Physiotherapy, Faculty of Physical Culture, Palacky University Olomouc, Czech Republic

eInstitute of Biostatistics and Analyses, Faculty of Medicine, Masaryk University, Brno, Czech Republic

${ }^{f}$ National Screening Centre, Institute of Health Information and Statistics of the Czech Republic, Prague, Czech Republic

${ }^{g}$ Department of Radiology, University Hospital Hradec Kralove and Faculty of Medicine in Hradec Kralove, Charles University, Hradec Kralove, Czech Republic

${ }^{h}$ Pulmonary Department, University Hospital Hradec Kralove and Faculty of Medicine in Hradec Kralove, Charles University, Hradec Kralove, Czech Republic

Corresponding author: Kristian Brat, e-mail: kristian.brat@seznam.cz

\section{CONTENTS}

1. Introduction

2. Definition and Pathophysiology

3. Risk factors

4. Epidemiology

5. Risk assessment

6. Diagnosis of COPD

7. Initial classification of a COPD case

8. Clinical phenotypes of COPD

8.1. Frequent exacerbator phenotype

8.2. Bronchitic phenotype

8.3. Emphysematous phenotype

8.4. Asthma/COPD overlap

8.5. Bronchiectases with COPD overlap

8.6. Phenotype of pulmonary cachexia

8.7. Coincidence/co-presence of more treatable traits/ phenotypes.

9. COPD screening in the Czech Republic

10. Treatment

10.1. Treatment strategy

10.2. Risk elimination

10.3. Basic treatment

10.4. Phenotype-specific treatment

10.4.1. Frequent exacerbator phenotype

10.4.2. Bronchitic phenotype

10.4.3. Emphysematous phenotype

10.4.4. Asthma/COPD overlap

10.4.5. Bronchiectases with COPD overlap

10.4.6. Phenotype of pulmonary cachexia

10.4.7. Multiple phenotypes' co-presence

10.5. Treatment of respiratory failure, lung transplantation and palliative care (end-of-life care)

10.6. Treatment of comorbidities

11. Flow Chart of Management of Stable COPD

12. Future directions and developments

\section{INTRODUCTION}

Chronic Obstructive Pulmonary Disease (COPD) represents a serious disease or, more precisely, a heterogeneous syndrome, affecting hundreds of millions of people world- wide $^{1}$. The disease is associated with significant mortality, morbidity and reduced quality of life.

The Global Initiative for Chronic Obstructive Lung Disease (GOLD) regularly (on a yearly basis) publishes a report dedicated to strategy of COPD management. This report is used by physicians worldwide as a basic strategy document, defining basic terms and concepts. However, several national or international COPD management guidelines or recommendations have been developed and published previously, that more precisely respect the scope, structure and individual characteristics of local healthcare systems ${ }^{1-10}$. In contrast to other guidelines, this position paper is based on clinical phenotypes of COPD and employs the treatable traits concept for COPD treatment.

Experts from the Czech national board of diseases with bronchial obstruction have been commisioned by the Czech Pneumological and Phthisiological Society (CPPS) in order to draft an update on previous (2013) recommendations for diagnosis, management and treatment of stable COPD (ref. ${ }^{11}$ ). The updated document has been discussed and revised at the Czech National Consensus Conferences in November 2018 (Hradec Kralove), April 2019 (Hradec Kralove), and June 2019 (Prague). After incorporation of the comments, the prefinal version of the document has been established. Final polishing of this official position paper has been perfomed by members of CPPS from January to August 2020 (during three expert meetings and several web based session).

The intention of the authors was to set this evidencebased position paper into the context of daily clinical practice and the current health care system of the Czech Republic. Currently, all treatment components are available in the Czech Republic; mandatory health insurance of all residents covers most of the treatment expenses including rehabilitation program, alpha-1 antitrypsin augmentation, lung transplantation, long-term oxygen treatment, and high-intensity non-invasive ventilation support. Above that, more than $90 \%$ of care for patients with COPD is concentrated in the hands of respiratory specialists. This means, that literally almost every patient with COPD has unlimited access to lung CT scanning, advanced lung function assessment and full-scale phar- 
macological and non-pharmacological treatment available in the Czech Republic ${ }^{11}$. Special emphasis is placed on complex management of COPD and related comorbidities, personalized approach to care and on new scientific knowledge published since the previous Czech COPD management document ${ }^{11}$.

\section{DEFINITION AND PATHOPHYSIOLOGY}

COPD is a preventable and treatable disorder that is characterized by persistent respiratory symptoms and airflow limitation that is due to lower airway and/or alveolar abnormalities usually caused by significant exposure to noxious particles and/or gases. Besides these risk exposures, host factors (genetic factors, altered childhood lung growth, and accelerated premature aging) predispose individuals to develop COPD. The most common respiratory symptoms include breathlessnes and chronic cough with or without sputum production. The above mentioned symptoms may be under-reported by COPD patients ${ }^{1,12-15}$.

COPD is a heterogeous condition with a number of pulmonary and extrapulmonary clinical features and concomitant chronic diseases. The pulmonary component of COPD is characterized by a partially reversible airflow limitation developing gradually due to prolonged abnormal inflammatory response and/or tissue abnormalities of the airways and lung parenchyma to noxious particles and gases ${ }^{1,16}$. Oxidative stress, protease-antiprotease imbalance and increased numbers of pro-inflammatory cells (neutrophils, alveolar macrophages, T-lymphocytes and innate lymphoid cells) are the main drivers of primarily non-infectious inflammation in COPD ( ref. $^{17}$ ). A majority of patients with COPD have a predominantly neutrophilic type of inflammation, however, approximately every one of four/five patients presents with concurrent eosinophilic inflammation $^{18,19}$.

The chronic inflammation leads to accelerated and progressive breakdown of elastic fibers, peribronchial fibrosis, destruction of alveolar walls, microvessels and small airways, airway remodelling and mechanisms of chronic mucus hypersecretion ${ }^{17,21,22}$. Progressive airflow limitation and airway remodelling leads to air trapping, static and dynamic hyperinflation, gas exchange abnormalities and to decreased exercise capacity and physical activity $^{22,23}$. The above listed mechanisms are expressed unequally and variably in individual patients, resulting in various types of clinical presentation. Nowadays, the "clinical phenotypes" concept is emerging, meaning "a single or combination of disease attributes that describe differences between individuals as they relate to clinically meaningful outcomes" to differentiate between various disease patterns and their clusters in specific subpopulations of COPD individuals $\mathrm{s}^{3,11,24-26}$.

Multiple systemic effects have been described in patients with COPD. Increased levels of circulating inflammatory mediators and acute-phase proteins are drivers or at least contributors to the development of comorbidities, including cardiovascular diseases, skeletal muscle dysfunction, osteoporosis, depression, cachexia, diabetes mellitus or sleep apnoea syndrome $\mathrm{e}^{27-32}$. In consequence, persistent systemic inflammation is associated with higher risk of exacerbation and mortality ${ }^{33}$. COPD is also considered a proven pre-cancerous condition ${ }^{27,34}$.

Besides the already understood mechanisms, pulmonary cellular senescence is now considered a potent driver mechanism of COPD pathogenesis. Senescent cells secrete pro-inflammatory proteins and molecules, leading to chronic inflammation. Understanding the process of pulmonary cellular senescence may allow us to identify new therapeutic targets in the future ${ }^{35}$.

\section{RISK FACTORS}

Tobacco smoking - including second-hand smoke and passive exposure - is considered the main cause of COPD. Besides smoking, other environmental exposures such as household air pollution, occupational particulates, ozone and ambient particulate matter were found important risk factors of COPD development ${ }^{36}$.

There are also studies showing association between airflow limitation in childhood and greater risk of COPD and asthma-COPD overlap syndrome (ACOS) development in adulthood ${ }^{37}$. The higher likelihood of developing COPD was also observed in low birth weight infants ${ }^{38,39}$, childhood asthma ${ }^{40,41}$ and patients with frequent respiratory infections during childhood ${ }^{38,40}$. Evidence also supports that tuberculosis ${ }^{42,43}$ and HIV patients are at higher risk of COPD development ${ }^{44}$.

However, these factors are unlikely to be the only reason of developing COPD. In a small proportion of nonsmokers, a genetic component to the disease or specific interactions between genetic and epigenetic factors and effects of the environment may play an important role $\mathrm{e}^{45}$. The most documented genetic risk factor of COPD is alpha-1 antitrypsin deficiency (AATD) ( ref. $^{46,47}$ ). However, other genetic polymorphisms, including single genes encoding glutathione S-transferase, matrix metalloproteinases or superoxide dismutase, may also be associated with the pathogenesis of the disease $\mathrm{s}^{48-50}$.

\section{EPIDEMIOLOGY}

Smoking epidemics in the developing countries, general aging of populations, and increased environmental exposure to air pollution are responsible for the increasing global incidence and prevalence of the disease $\mathrm{e}^{51,52}$. The latest worldwide prevalence was estimated at $11.7 \%$ (ref. ${ }^{52}$ ). An estimated $12.4 \%$ of the EU population suffer from COPD $\left(\right.$ ref. ${ }^{53}$ ). In the Czech Republic, the recently estimated prevalence is around $6.7 \%$, i.e., around 710,000 patients per the 10,65 million population of the country ${ }^{54}$.

According to the latest epidemiological data, COPD currently ranks fourth, however, by 2020, it was projected to become the third worldwide leading cause of death from non-communicable diseases ${ }^{1,51}$. Current mortality data (for the year 2020) are yet not available. The disease claims around 3 million lives in the world annually ${ }^{55}$. In 
the EU, the mortality trend was linearly decreasing during the period between 1994 and 2010 (ref. ${ }^{56}$ ). Following a period of notable increase since the 2000-10 decade, mortality from COPD in the Czech Republic was about stable between the years 2015 and 2018, with 3,200-3,500 deaths reported annually ${ }^{54,57}$.

\section{RISK ASSESSMENT}

Prognostic assessment is one of the key issues regarding the disease management, offering the opportunity to identify high-risk patients requiring more assertive treatment approach. Traditionally, FEV, was the most widely used parameter for basic prognostic evaluation, reflecting the association between progressive lung function decline and increasing mortality risk $^{58}$.

In the last two decades, composite tools for long-term prognosis assessment have been constructed, including the ADO, BODE and related indices ${ }^{58,59}$. The scoring system of the BODE and the score-specific four-year mortality risk are described in the article by Celli et al. ${ }^{58}$. Recently, a new-generation multidimensional prognostic instrument, the CADOT index, has been introduced. The CADOT showed slightly better prognostic properties compared to ADO and BODE indices and prevented the specific problems associated with the use of BODE (ref. ${ }^{60}$ ). The CADOT incorporates also chronic heart failure that has strong linkage to mortality risk and also to functional impairment of the lungs ${ }^{61}$. As such, the CADOT instrument offers an alternative to the BODE index, if the 6-MWT (or an other component of the BODE) is not feasible. If calculation of BODE or CADOT score is not possible, a significantly higher risk of long-term mortality should be expected in group B patients with chronic hypoxemia $\left(\mathrm{PaO}_{2}<7.3 \mathrm{kPa}\right)$ and in group $\mathrm{D}$ patients, irrespective of hypoxemia ${ }^{62}$.

\section{DIAGNOSIS OF COPD}

The elementary requirements for diagnosis of COPD consist of spirometric confirmation of post-bronchodilator (post-BD) expiratory airflow limitation (bronchial obstruction) (Fig. 1). Spirometry should be done in all individuals with chronic respiratory symptoms (dyspnoea
GOLD 1

FEV $/$ FVC $<0.7$

$\mathrm{FEV}_{1}>80 \%$
GOLD 2

$\mathrm{FEV}_{1} / \mathrm{FVC}<0.7$

FEV $79-50 \%$

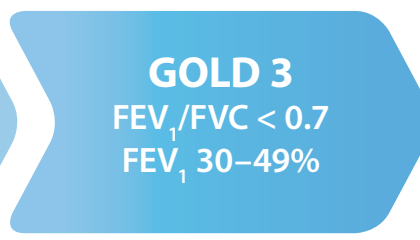

GOLD 4

$\mathrm{FEV}_{1} / \mathrm{FVC}<0.7$

$\mathrm{FEV}_{1}<30 \%$

Fig. 1. GOLD stages (according to post-BD spirometry of COPD patients)

Table 1. Alternative diagnoses to COPD.

\begin{tabular}{|c|c|c|}
\hline Alternative diagnosis & $\begin{array}{l}\text { Clinical presentation similar to COPD } \\
\text { (dominant symptom(s) in the bold) }\end{array}$ & $\begin{array}{l}\text { Confirmation of alternative diagnosis } \\
\text { (the most important options in the real-life practice) }\end{array}$ \\
\hline Bronchial asthma $^{\#}$ & $\begin{array}{l}\text { Cough, dyspnoea, wheezing, } \\
\text { sputum production }\end{array}$ & $\begin{array}{l}\text { Normal TLco, periods without bronchial } \\
\text { obstruction, normal chest HRCT }\end{array}$ \\
\hline Bronchiolitis & Cough, dyspnoea & $\begin{array}{l}\text { Chest HRCT inspiratory/expiratory (with mosaic } \\
\text { pattern) }\end{array}$ \\
\hline Bronchiectases $^{\# \#}$ & Cough, sputum production, exacerbation & Chest HRCT (bronchiectases signs) (ref. ${ }^{66,67}$ ) \\
\hline Cystic fibrosis & Cough, sputum production, dyspnoea & Sweat test $(>60 \mathrm{mmol} / \mathrm{l})\left(\right.$ ref. $\left.{ }^{68}\right)$ \\
\hline $\begin{array}{l}\text { Primary ciliary } \\
\text { dyskinesia }\end{array}$ & Cough, sputum production, exacerbation & Nasal Nitric Oxide $\left(<105\right.$ ppb) $\left(\right.$ ref. $\left.{ }^{69,70}\right)$ \\
\hline Extraesophageal reflux & $\begin{array}{l}\text { Cough, especially after lying in supine position, } \\
\text { sputum production, aspiration attack }\end{array}$ & $\begin{array}{l}\text { Laryngoscopy/Gastroscopy, pH metry, esophageal } \\
\text { impedance }\end{array}$ \\
\hline $\begin{array}{l}\text { Tracheobronchomalacia } \\
\text { (intrathoracic collapse) }\end{array}$ & Cough, wheezing, dyspnoea & $\begin{array}{l}\text { Bronchoscopy, dynamic chest HRCT during } \\
\text { spirometry }\end{array}$ \\
\hline Tracheal stenosis (fixed) & Cough, wheezing, dyspnoea & Bronchoscopy \\
\hline Sarcoidosis & Cough, wheezing & Chest HRCT \\
\hline Pulmonary embolism & Dyspnoea & Chest CT with contrast, D-dimers \\
\hline Heart failure & Dyspnoea, cough & Heart ultrasound, chest X-ray, NTpro-BNP* \\
\hline
\end{tabular}

\footnotetext{
\# Except for patients who have simultaneously present and balanced features of both diseases (asthma and COPD overlap - ACO)

\#\# Except for patients who have simultaneously present and balanced features of both diseases (bronchiectasis and COPD overlap - BCO)

* NTpro-BNP = N-terminal prohormone of brain natriuretic peptide
} 
with exercise limitation and/or cough and/or sputum production), particularly in case of long-term risk exposure - see above ${ }^{63}$. Expiratory airflow limitation was clearly defined by the European Respiratory Society as a decrease in $\mathrm{FEV}_{1} / \mathrm{VC}$ below the lower limit of normal values (LLN) (ref. ${ }^{64,65}$ ). Global Initiative for Chronic Obstructive Lung Disease (GOLD) simplifies the view on spirometric diagnosis of COPD to fit to the health care based on general practitioners. From the GOLD perspective, any person with post-BD $\mathrm{FEV}_{1} / \mathrm{FVC}<0.7$ is considered a COPD case. In order to establish the definite COPD diagnosis, all alternative diagnoses associated with bronchial obstruction should be excluded - Table 1 (ref. $^{1}$ ).

COPD individuals exhibit gas trapping and increased lung hyperinflation from early stages of the disease. These important features can be documented by bodyplethysmography. Measurement of transferfactor $\left(\mathrm{TL}_{\mathrm{CO}}\right)$ for carbon monoxide provides additional information on the functional impact of emphysema and cardiovascular comorbidities in COPD subjects ${ }^{1,64}$.

Worse lung function, more dyspnoea, higher comorbidity burden, and non-stable (exacerbated) course of COPD are associated with elevated overall health risks among COPD population. The above mentioned risk factors are useful for assessing the appropriate depth of the initial examination of a newly diagnosed case (Fig. 2).

\section{INITIAL CLASSIFICATION OF A COPD CASE}

This position paper uses combined classification including COPD stages ( 1 to 4 ), COPD groups (A to D) according to GOLD (ref. ${ }^{1}$ ) and assessment of one or more clinical phenotype(s), if it is (they are) present.

At initial examination of COPD individuals, a comprehensive assessment of the patient using a history of worsening episodes called exacerbations and evaluation of respiratory symptoms (using the CAT questionnaire and/ or the modified MRC dyspnoea scale) is recommended (Fig. 3).

The current GOLD 2020 strategy recommends that each patient be marked with the letter A-B-C-D, indicating a specific disease group. Health systems based on general practitioners propose initial pharmacological treatment according to A-D groups ${ }^{1}$. In the conditions of different health care system in the Czech Republic, this is not necessary, however, we still find the A-D groups useful since they describe the extent of symptoms and exacerbations (Fig. 4).

Group A represents asymptomatic subjects in early stage of the disease, these patients can be successfully treated by general practitioners (GPs). In contrast, group $\mathrm{B}$ deserves particular attention as it consists of comorbidity-burdened patients with a less pronounced deterioration in lung function, though with a substantial mortality

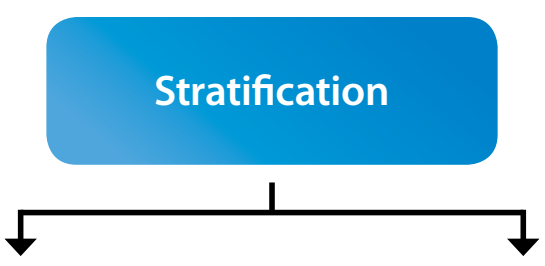

LOW risk

(Must meet all criteria)

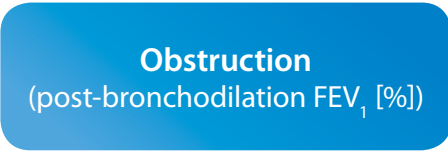

Dyspnoea (mMRC)

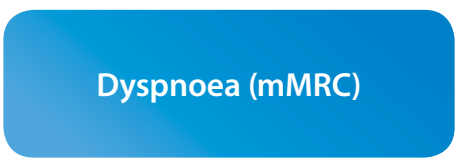

Exacerbations

(previous year)

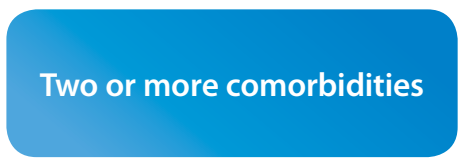

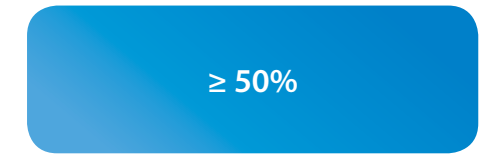

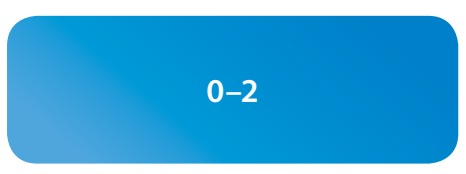

0-1 (no admission)
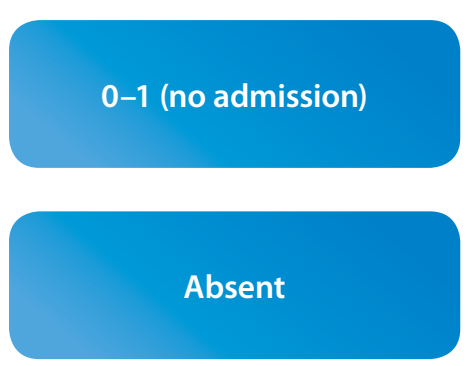

HIGH risk

(Must meet at least 1 criterion)
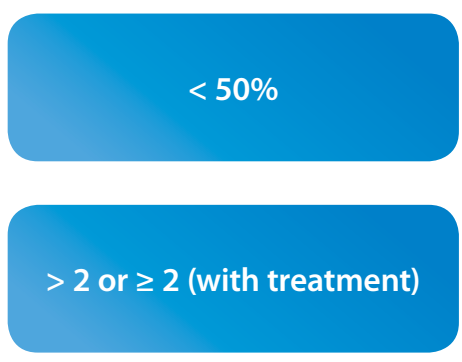

2 or more, or 1 admission

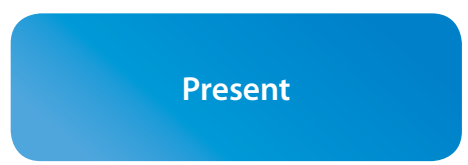

Fig. 2. Health risk assessment modified according to Miravitlles et al. (ref. ${ }^{3}$ ). 


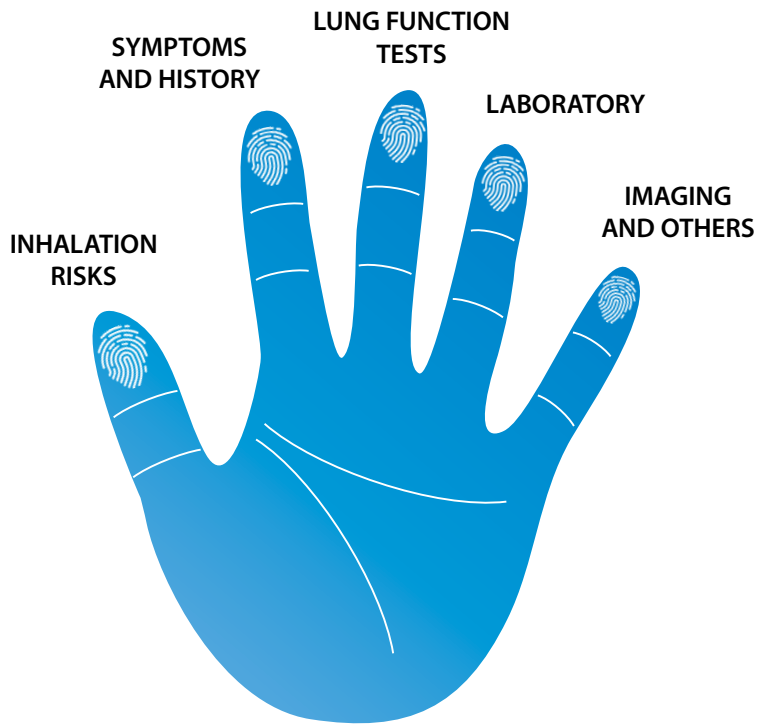

Fig. 3. Initial diagnostic procedures in new COPD cases.

\author{
$1^{\text {st }}$ finger: INHALATION RISKS \\ Smoking and/or occupational risks and/or air pollution \\ $2^{\text {nd }}$ finger: SYMPTOMS AND HISTORY \\ CAT (or mMRC dyspnoea scale) \\ PATIENT HISTORY related to COPD and other diseases \\ $3^{\text {rd }}$ finger: LUNG FUNCTION TESTS \\ SPIROMETRY (before and after salbutamol) in low risk patients \\ SPIROMETRY + LUNG VOLUMES + DIFFUSION (in high risk patients) \\ 6-MINUTE WALKING TEST (alternatives: CPET, 1-MINUTE SIT TO STAND TEST) \\ $4^{\text {th }}$ finger: LABORATORY \\ BIOCHEMISTRY (A1AT, ...) + HAEMATOLOGY (EOSINOPHILS, ...) \\ SPUTUM (culture) \\ $5^{\text {th }}$ finger: IMAGING AND OTHERS \\ CHEST X-RAY (or CHEST CT in high risk patients) \\ ECG (and HEART ULTRASOUND in high risk patients) \\ ABDOMINAL SONOGRAPHY (in cases of cachexia) \\ POLYSOMNOGRAPHY (in cases of non-mild obesity)
}

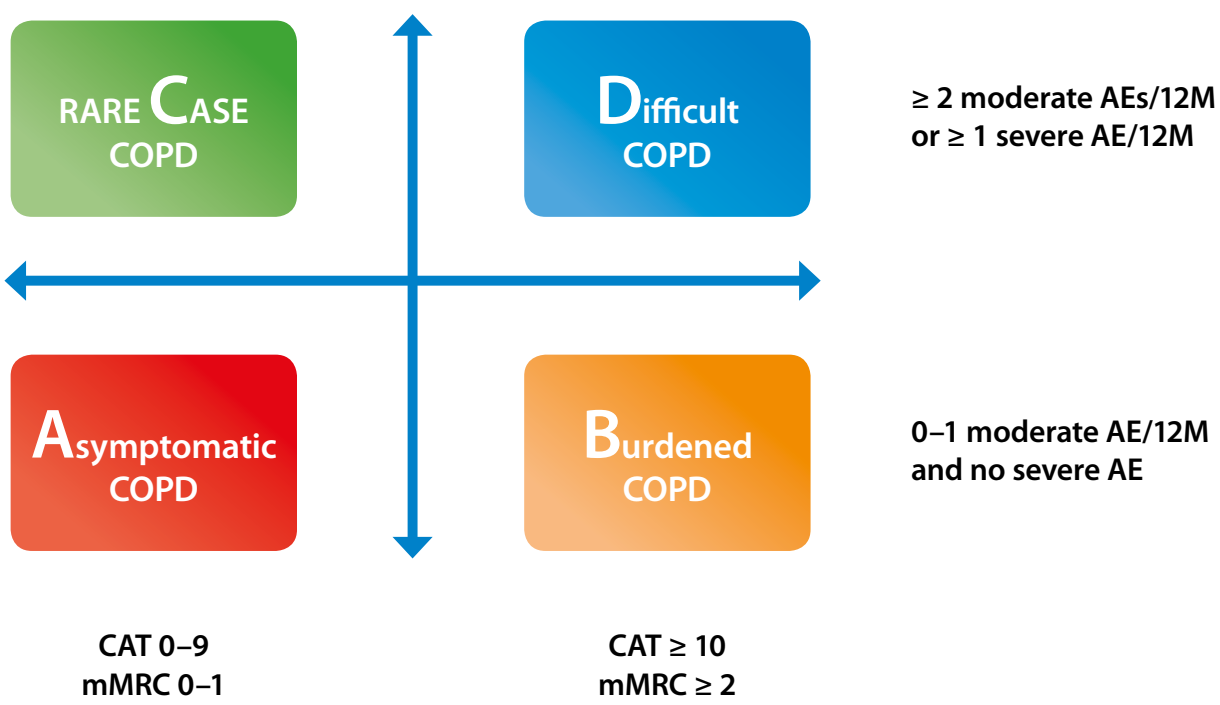

Fig. 4. GOLD groups according respiratory symptoms and number of exacerbations in the past 12 months.

risk $^{62}$. Rare cases of oligo-symptomatic patients, comprising the small group $\mathrm{C}$, can be usually found in the general population, but rarely in the pulmonologist's care. The highest mortality risk is associated with group D (difficult). Subjects of this category are extremely threatened by high respiratory and cardiovascular morbidity and mortality rates. Hence the monitoring and treatment of such individuals has to be thorough and comprehensive in every aspect.

A simple assessment of COPD severity with postbronchodilator spirometry (stages 1 to 4 ) reflects the deterioration of lung function and the extent of bronchial obstruction. Despite the severity of bronchial obstruction has only weak correlation with symptoms and course of the disease, $\mathrm{FEV}_{1}$ has a significant role in prognosis prediction and in some therapeutic decisions ${ }^{1}$.

\section{CLINICAL PHENOTYPES OF COPD}

COPD is not a rigid and uniform condition, it likely represents a continuum of different sub-diseases that may share biological mechanisms (i.e., endotypes), and present with similar clinical, functional, imaging and/or biological features (i.e., phenotypes or phenotypical labels) which may require specific treatment (i.e., constituting specific treatable traits) (ref. ${ }^{25,71,72}$ ). In our concept, the six pre-defined clinical phenotypes are also considered independent treatable traits. For each treatable trait, specific pharmacological and non-pharmacological therapies are defined within this document.

Currently, there are two ways to delineate phenotypical features in each particular COPD case: the "Spanish approach" means that one COPD patient is described by one "clinical phenotype". The Czech approach is that the COPD patient may be characterized by one or more phe- 


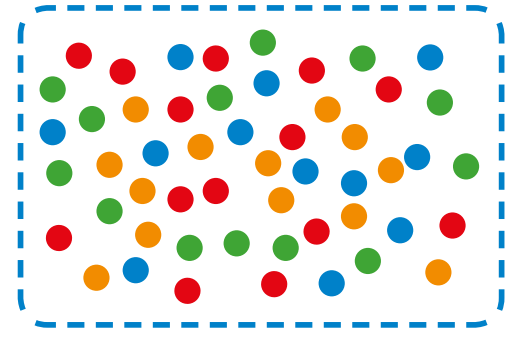

A - COPD as a heterogeneous disease

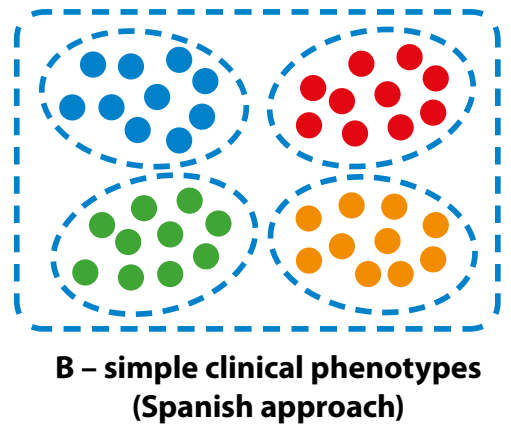

(Spanish approach)

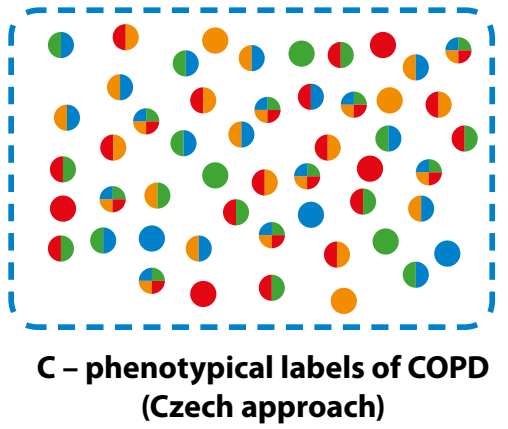

Fig. 5. Elementary concepts of COPD heterogeneity proposed by Agusti (ref. ${ }^{71}$ ).

Table 2. Phenotypical labels in COPD - characteristics.

\begin{tabular}{|c|c|c|c|c|c|c|c|}
\hline $\begin{array}{l}\text { Methods / phenotypical labels } \\
\text { or treatable traits }\end{array}$ & $\mathrm{CB}$ & EMPH & AE's w. INF & AE's w. eo & $\mathrm{ACO}$ & $\mathrm{BCO}$ & CACHEXIA \\
\hline Subnormal BMI (and FFMI) & & + & & & & & ++ \\
\hline Daily sputum production & ++ & & & & & + & \\
\hline Repeated infections of lower airways & + & & ++ & + & & + & \\
\hline Repeated AE's & & & ++ & ++ & & & \\
\hline History of $\mathrm{AB}<40$ years & & & & & ++ & & \\
\hline History of haemoptysis (any time) & & & + & & & + & \\
\hline Bodyplethysmography & & ++ & & & & & \\
\hline Transferfactor (diffusion) & & ++ & & & & & \\
\hline Exercise and daily activity & & + & & & & & + \\
\hline$\downarrow$ A1AT (blood) & & ++ & & & & & \\
\hline$\uparrow$ Eosinophils (blood) & & & & ++ & ++ & & \\
\hline Sputum culture is positive & + & & + & & & + & \\
\hline HRCT emphysema signs & & ++ & & & & & \\
\hline HRCT bronchiectases signs & & & & & & ++ & \\
\hline HRCT airway disease signs & + & & & & & & \\
\hline
\end{tabular}

A1AT - alpha-1 antitrypsin

$\mathrm{AB}$ - bronchial asthma

ACO - asthma/COPD overlap

AE's w. eo - acute exacerbation (with eosinophilia)

AE's w. INF - acute exacerbation (with infection)

$\mathrm{BCO}$ - bronchiectases and COPD overlap

BMI - body mass index

notypes/phenotypical labels - one patient=one or more phenotypes $^{3,11,62,73-75}$ (Fig. 5, Table 2).

Clinical phenotypes in individual patient may change over time, for example symptoms of chronic bronchitis or exacerbation rate can be improved after treatment. In these cases we prefer not to use the term "change of phenotype" but rather "achievement of clinical control" or "stabilisation of phenotype". In case of new phenotype development (e.g., new bronchiectases or frequent exacerbations), treatment should be adjusted to the actual clinical disease presentation to maintain maximal control of COPD.

All patients with COPD independently of the presence of clinical phenotype(s):

The most common clinical presentation of COPD is limitation of daily living activites due to breathlessness sensation. Dyspnoea first occurs during high-intensity physical exercise, later during milder effort, finally at rest,
CB - chronic bronchitis

HRCT - high resolution computed tomography

EMPH - emphysema

FFMI - fat free mass index

++ Essential meaning

+ Auxiliary meaning

eventually resulting in physical inactivity, lifestyle change and social isolation ${ }^{1,76-78}$. Chronic fatigue is a highly prevalent sign in the COPD population. Fatigue poorly correlates with the degree of airflow limitation, but perceived fatigue seems to be a key factor in the decreasing quality of life $\mathrm{e}^{79,80}$.

\subsection{FREQUENT EXACERBATOR PHENOTYPE}

The long-term stable course of COPD can be intermittently interrupted in some patients by sustained worsening which exceed the normal day-to-day symptom variations. These attacks of symptoms worsening that last $\geq 2$ days and require change in medication and/or hospitalization are called acute exacerbations (AEs) (ref. ${ }^{81,82}$ ). AEs have a significant and prolonged impact on health status and outcomes, and negative effects on pulmonary functions. 
AEs with the need of antibiotic treatment and/or systemic corticosteroids' use are called moderate AEs. Those AEs resulting in hospitalization are considered severe AEs. The best threshold to distinguish "frequent exacerbators" and non-frequent exacerbators are two moderate-to-severe exacerbations per year. Therefore, the "frequent exacerbator" phenotype should be defined by at least two AEs treated in the past year. Frequent exacerbators have more pronounced airflow limitation, higher degree of symptoms and health-related quality of life impairment ${ }^{83}$. A significant proportion of AEs are unreported and therefore left untreated, leading to a poorer prognosis compared to those treated adequately. COPD exacerbations are heterogeneous, and various phenotypes have been proposed which differ in biologic basis, prognosis, and response to therapy. Frequent exacerbations are the strongest predictor of future exacerbation frequency, suggesting a consistent phenotype ${ }^{84-87}$. Therefore, reduction of AEs has beneficial impact on patient outcomes and prognosis ${ }^{81,88}$.

\subsection{BRONCHITIC PHENOTYPE}

COPD patients with the bronchitic phenotype commonly experience cough, which is productive (with longterm presence of phlegm) in about $60 \%$ of cases $^{89,90}$. CB subjects report worse respiratory symptoms (diurnal + nocturnal cough and phlegm) and experience higher risk of COPD exacerbations ${ }^{91,92}$.

\subsection{EMPHYSEMATOUS PHENOTYPE}

Patients with pulmonary emphysema usually experience dyspnoea and have no chronic sputum expectoration (if there's no coincidence with bronchitic phenotype).

Emphysematous patients are clinically characterized by a more prevalent dyspnoea than any other COPD patients: A) early-morning and daytime dyspnoea in cases of mild emphysema, and B) diurnal + nocturnal dyspnoea in cases of severe emphysema. In most cases, chest high resolution computed tomography (HRCT) is necessary to confirm the presence of pulmonary emphysema. In addition, CT scans uncover the type of emphysema, its distribution and extent. Above that, CT scans help to exclude other lung diseases (tumours, lung fibrosis) and are also beneficial for bronchiectases detection ${ }^{92-95}$.

The Fleischner Society of radiologists proposed a statement that describes and defines the phenotypic abnormalities identifiable on visual and quantitative HRCT images in subjects with COPD. Emphysema is classified as centrilobular (subclassified as trace, mild, moderate, confluent, and advanced destructive emphysema), panlobular, and paraseptal (subclassified as mild or substantial). Additional important visual features include airway wall thickening, inflammatory small airways disease, tracheal abnormalities, interstitial lung abnormalities, pulmonary arterial enlargement, and bronchiectases ${ }^{96-98}$. Prior to CT scanning, clinical suspicion on emphysema should be made in patients with a "barrel chest", with radiological signs of emphysema on a chest X-ray and/or with lung hyperinflation at pulmonary function tests.

\subsection{ASTHMA-COPD OVERLAP (ACO)}

ACO is characterized by persistent airflow limitation with several clinical features of bronchial asthma and several features typical for COPD. ACO may be a special phenotype of chronic obstructive airway diseases, in which asthma and COPD are located at the two opposite ends. The prevalence of ACO varies considerably due to variability of criteria for its diagnosis. Patients with ACO utilize a large proportion of medical resources because they experience more symptoms and AEs compared to those with asthma or COPD alone ${ }^{99,100}$. Although definitions of ACO vary, a most typical presentation of ACO includes persistent bronchial obstruction in a COPD patient older than 40 years with either a previous history of asthma or large bronchodilator reversibility ${ }^{101}$. ACO includes two different conditions such as: a) asthma of smokers with airway remodeling and incomplete airflow reversibility, b) eosinophilic phenotype of COPD (ref. ${ }^{102}$ ). Compared to their counterparts with asthma or COPD alone, patients with ACO have significantly worse respiratory symptoms, poorer respiratory quality of life, and increased exacerbations' and hospital admissions' risk ${ }^{103}$

The simplified current Spanish Respiratory Society consensus defines ACO as: (a) the presence of chronic airflow limitation in a smoker or ex-smoker (more than 10 pack-years) patient $\geq 35$ years old; (b) with current diagnosis of asthma; and/or (c) the presence of a strongly positive bronchodilator test $(\geq 15 \%$ and $\geq 400 \mathrm{~mL})$ or the presence of eosinophilia in peripheral blood $(\geq 300$ eosinophils/ $\mu \mathrm{L})\left(\right.$ ref. $\left.^{103-105}\right)$.

The Czech Pneumological and Phthiseological Society proposed the persistent presence of either two major criteria, or one major and two minor criteria that are typical for coexistence of both conditions in ACO. These approach is slightly more restrictive than the Spanish one, in order to increased specificity of ACO phenotypical label (Fig. 6) (ref. $\left.{ }^{75,106}\right)$.

\subsection{BRONCHIECTASES WITH COPD OVERLAP}

Parallel to COPD, a minority of patients suffer from bronchiectases (defined as an abnormal dilatation of the bronchi, usually in two or more pulmonary lobes, without any other known cause). Above that, bronchiectases may also develop during long-term course of COPD. The prevalence of bronchiectases in COPD patients increases with higher stage of the disease (highest prevalence is present in COPD stage 4).

$\mathrm{BCO}$ is associated with increased lung inflammation and worse lung function ${ }^{107,108}$. Bronchiectases should be considered in patients with COPD with greater severity of symptoms who often suffer from exacerbation or 

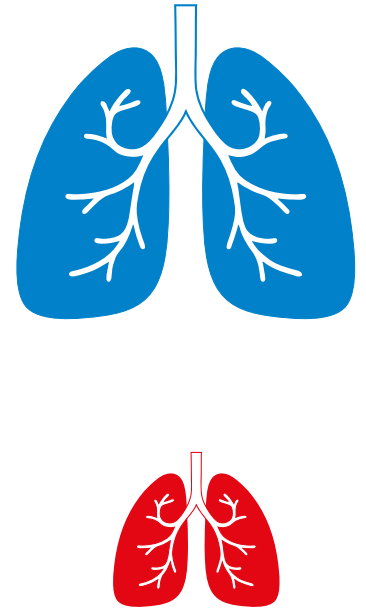

Major criteria:

a) strongly positive bronchodilator test (change $\mathrm{FEV}_{1} \geq 15 \%$ and $\geq 400 \mathrm{ml}$ )

b) history of bronchial asthma before 40 years established by physician

c) presence of eosinophilia in peripheral blood ( $\geq 300$ eosinophils/ $\mu \mathrm{l}$ )

d) sputum eosinophil count $\geq 3 \%$

e) positivity of metacholine bronchial challenge test

f) increased FeNO (> 45-50 ppb) in the stable phase of COPD

Fig. 6. Asthma and COPD overlap (ACO) criteria.

repeated respiratory infections, especially in those who isolate Pseudomonas aeruginosa in sputum ${ }^{109-112}$.

\subsection{PHENOTYPE OF PULMONARY CACHEXIA}

Approximately $5-10 \%$ of COPD patients (especially those with severe bronchial obstruction) display a tendency towards gradual, slow, and unintentional decrease in body weight and altered body composition (simplified criterion BMI <21), particularly in fat-free mass i.e. muscle tissue (decrease in fat-free mass index (FFMI) $<16 \mathrm{~kg} / \mathrm{m}^{2}$ in men, $<15 \mathrm{~kg} / \mathrm{m}^{2}$ in women) (ref. ${ }^{62,113-118}$ ). Pulmonary cachexia is associated with increased mortality risk among COPD patients ${ }^{119}$.

\subsection{COINCIDENCE/CO-PRESENCE OF MORE PHENOTYPES}

Coincidence of two specific phenotypes: chronic bronchitis + frequent excerbator or $\mathrm{BCO}+$ frequent exacerbator are associated with a more negative influence of disease on patients quality of life and the course of the disease ${ }^{77,87}$. The most severe COPD patients with clinically balanced triple mixture of emphysematous + chronic bronchitic + frequent exacerbation phenotypes suffer from severe symptoms, poorer quality of life, sleep disturbances, and highest levels of depression and anxiety $^{92}$. Co-presence of emphysema, cachexia and frequent exacerbations is associated with poorest patients' prognosis ${ }^{120}$.

Table 2 gives an overview of those six elementary COPD phenotypical labels/treatable traits, which occasionally might occur simultaneously in real-life practice (e.g., emphysematous COPD + pulmonary cachexia, or bronchitic COPD and frequent exacerbator). All the above mentioned forms of COPD can move, usually after many years, towards the development of chronic respiratory failure (hypoxemic, and/or hypercapnic) which is often associated with pulmonary hypertension leading towards an overload or failure of the right ventricle. Individuals in an advanced stage of the disease are referred to as having terminal COPD.

COPD is often accompanied by other diseases or comorbidities: lung cancer, ischemic heart disease, lung fibrosis, pneumoconiosis, chronic heart failure, anxiety, depression, osteoporosis, anemia, peptic ulcer, gastroesophageal reflux disease and obstructive sleep apnoea $^{1,121,122}$.

\section{COPD SCREENING IN THE CZECH REPUBLIC}

Targeted early detection of still undiagnosed COPD subjects in the high risk (smokers or exsmokers) and symptomatic (at least one respiratory symptom) population is extremely effective ${ }^{63,123-125}$.

Early detection programmes of various diseases are part of the Czech national general health priorities previously declared in the strategy "Health 2020 - the national strategy for health support and protection and for disease prevention“. The National council for implementation and steering of programmes for early detection of diseases is the consultation authority of the Ministry of Health of the Czech Republic in this field. The programme for early detection of chronic obstructive pulmonary disease (COPD) was among others nominated by the National council for realization and received the necessary financial support.

The target population for this pilot project are "healthy persons" with pre-defined risk of COPD development, that means: history of cigarettes smoking (10 and more pack/years) and/or other inhaled risks, aged 40 - 69 years and with symptoms of breathlessness during common daily physical activities (faster walking, stairs climbing). Basic detection of persons at risk are provided by general practitions. Persons/smokers aged 40 - 69 years are actively contacted by their GP at any suitable occasion and are instructed and asked about their breathlessness. In case the patient fulfills the criteria of entering the program, he/she is referred to the cooperating pulmonologist. In the second step the pulmonologist instructs 


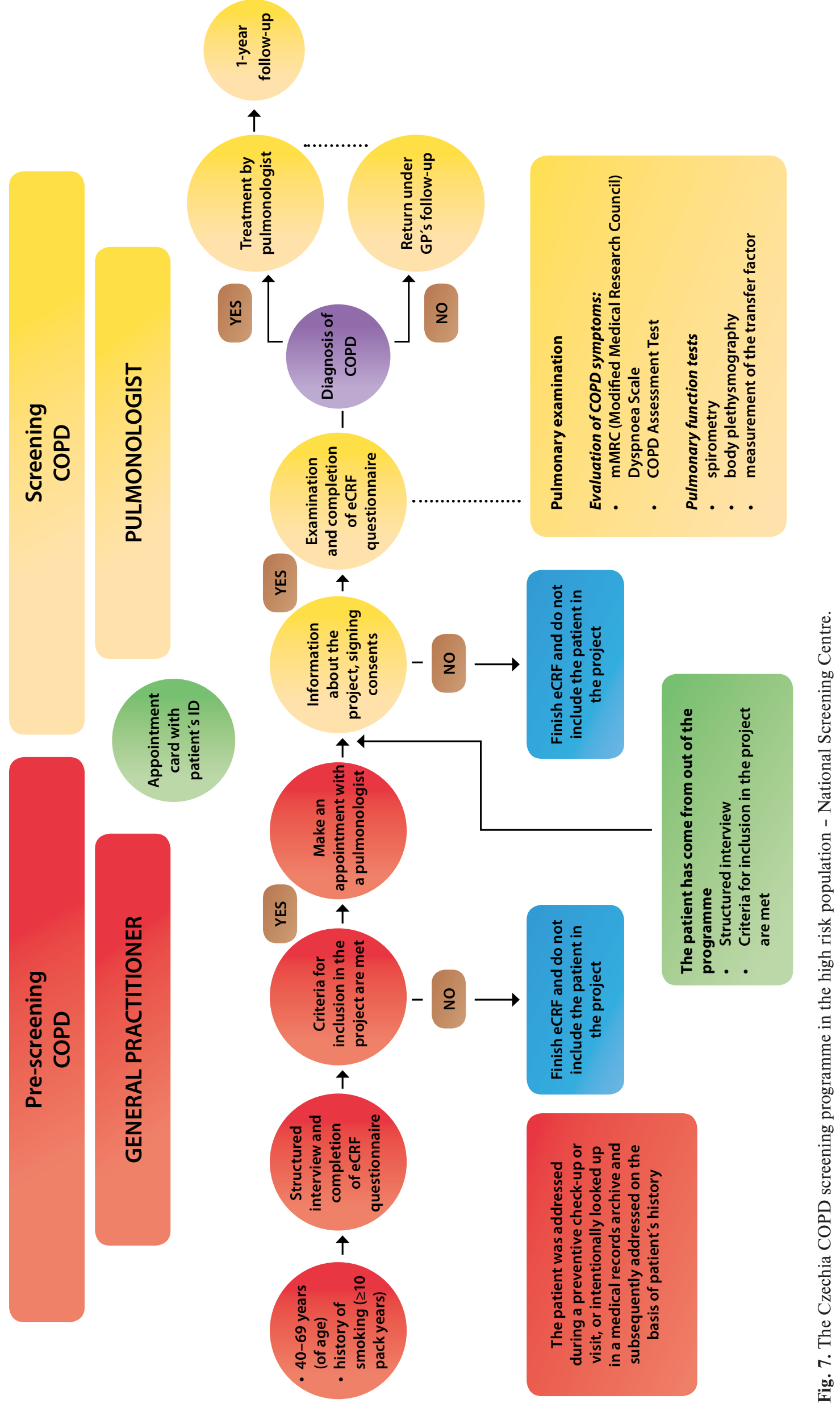




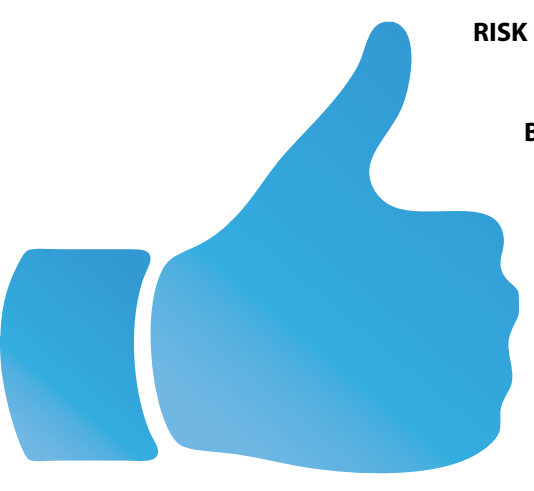

RISK ELIMINATION

BASIC TREATMENT

TREAT ALL TREATABLE TRAITS

RESPIRATORY FAILURE THERAPY

+ PALLIATIVE CARE

COMORBIDITY INTERVENTION

Fig. 8. COPD management strategy.

the patient in detail, asks the patient for his/her written consent and evaluates the mMRC dyspnea scale and CAT questionnaire. Lung function tests are performed: postbronchodilatory spirometry, bodyplethysmography and $\mathrm{TL}_{\mathrm{CO}}$ assessement. As a result, a diagnosis of COPD can be established, together with deeper assessment of its impact on symptoms and lung function (Fig. 7).

\section{TREATMENT}

\subsection{TREATMENT STRATEGY}

Treatment of COPD should reflect the complexity and heterogeneity of the disease and be tailored to each individual patient ${ }^{25}$. The aim of COPD treatment is to reduce symptoms, frequency and severity of exacerbations and improve exercise tolerance, prognosis and both short-term (disease control) and long-term outcomes (reduction in risk).

Treatment of COPD includes pharmacological and non-pharmacological therapy. According to the "five-finger concept", the treatment strategy is divided into five areas/strata: (1) risk elimination, (2) basic treatment, (3) phenotype-specific treatment, (4) treatment of respiratory insufficiency and supportive care/end-of-life care, and (5) treatment of comorbidities (Fig. 8).

\subsection{RISK ELIMINATION}

Identification of risk factors and elimination/reduction of exposure is a fundamental part of COPD treatment. It is necessary for all patients with COPD, regardless of other therapy.

\section{Smoking cessation}

Current opinions: Smoking cessation remains the most effective intervention that reduces lung function decline, improves responses to bronchodilators and inhaled corticosteroids and reduces the incidence of acute exacerbations and bronchopulmonary infections. Therefore, effort toward smoking cessation or at least reduction of smoking exposure should be made as a first intervention in all patients with COPD. Importantly, smokers with COPD are more nicotine dependent than smokers without COPD and also depression in smokers with COPD is more frequent when compared to smokers without COPD. Smokers with COPD usually experience low degree of smoking cessation self-efficacy and also are less motivated to quit than smokers without COPD; both factors are associated with low quitting rates ${ }^{126}$. In a systematic review, average 12-months continuous abstinence rates for smokers with moderate-to-severe COPD were estimated at $1.4 \%$ after usual care, $2.6 \%$ after minimal counselling, $6.0 \%$ after intensive counselling and $12.3 \%$ after intensive counselling supported by pharmacotherapy ${ }^{127}$. Individual counselling should be offered by each pulmologist, intensive counselling plus pharmacotherapy can be provided by a pulmologist or by experts in Nicotine Treatment Centres, constituting a network across Czech Republic. Pharmacotherapy available in the Czech Republic includes nicotine replacement therapy, bupropion and varenicline. The use of E-cigarettes to aid smoking cessation remains controversial ${ }^{1}$. Further recommendations regarding smoking cessation are described in special guidelines ${ }^{126}$.

\section{Treatment recommendations of the expert group:}

- Smoking cessation should be attempted in each patient.

- Psychosocial intervention should be supported by pharmacotherapy.

\section{Environmental air pollution, occupational exposures}

Current opinions: Urban air pollution contributes to the overall risk of COPD. Even more important is the role of urban air pollution as a trigger of exacerbations, particularly during seasonal worsening of urban and industrial air pollution. A specific case of environmental air pollution is passive exposure to tobacco smoke ("second hand smoking"), that may bring about respiratory symptoms and COPD exacerbation ${ }^{128}$. Occupational exposures, including organic and anorganic dusts, chemical agents and fumes are associated with increased risk of COPD development ${ }^{1}$. Elimination or reduction of exposure to occupational dusts and fumes, tobacco smoke and urban air pollutions are one of the first requirements of treatment regarding successful COPD treatment. 
Treatment recommendation of the expert group:

- Elimination of all risk factors should be attempted in each COPD individual.

\subsection{BASIC TREATMENT}

Basic treatment of COPD is assigned for each patient with COPD as a fundamental treatment, regardless of their phenotype. Basic treatment should be started immediately after COPD is diagnosed. Basic treatment includes regular therapy by long-acting bronchodilators, symptoms-relieving treatment by short-acting bronchodilators, pulmonary rehabilitation, inhalation training, vaccination, appropriate nutrition and psychological and social support.

\section{Long-acting bronchodilators}

Current opinions: Long-acting bronchodilators should be used as the first pharmacologic step in the treatment of all patients with COPD with persistent symptoms and who require regular treatment. Long-acting bronchodilators can be divided in two groups: Long-Acting Beta $_{2}$-Agonists (LABA), i.e.drugs with beta ${ }_{2}$ adrenergic effect (salmeterol, formoterol, olodaterol, vilanterol and indacaterol) and Long-Acting Muscarinic Antagonists (LAMA), i.e.drugs with anti-cholinergic effect (tiotropium, aclidinium, glycopyrronium, umeclidinium).

Most bronchodilators have a 12-hour duration of action and are administered twice daily, some have a 24-hour effect and can be administered once daily. Long-acting bronchodilators enable better control of symptoms, improve the quality of life, lung function and mortality and reduce the number of exacerbations and/or hospitalisations $^{129-133}$.

Pharmacological intervention with bronchodilator therapy is beneficial from early stages of COPD (ref. ${ }^{131,132,134,135}$ ). LAMA showed greater reduction of exacerbation rates than LABA (ref. ${ }^{136,137}$ ). LAMA improve the effect of pulmonary rehabilitation on exercise tolerance $^{138}$. Combined treatment with LABA and LAMA has better effect on lung function, dyspnea and quality of life compared to monotherapy. Dual LABA and LAMA treatment can reduce number of exacerbations sligtly better that LAMA alone ${ }^{134,135,139-141}$. A number of different inhaler devices exist and the choice of inhaler device and dosage should be tailored to individual patient's needs and abilities. There are limited data regarding de-escalation from dual bronchodilators to monotherapy. The latest GOLD document suggested that if addition of a second longacting bronchodilator does not improve symptoms, the treatment could be stepped down back to a single bronchodilator ${ }^{1}$. Similarly, a step down to monotherapy can be considered if the new component of dual bronchodilators is poorly tolerated or if serious new side effects occur.

\section{Treatment recommendations of the expert group:}

- Monotherapy with only LAMA or only LABA should be used in patients with lower degree of dyspnoea with
mMRC 0-1 and less impaired lung function with $\mathrm{FEV}_{1}$ $>50 \%$. If monoterapy is used, LAMA is preferred due to greater effect on reduction of exacerbation rates compared to LABA. One exception comes in patients with ACO where LABA is the preferable bronchodilator, usually combined with an inhaled corticosteroid (see below in Phenotype-specific treatment).

- Patients with more impaired lung function (FEV $\leq 50 \%$ ) and/or more symptomatic with mMRC $\geq 2$ should be treated by dual bronchodilator therapy (LAMA and LABA). Combined treatment with LABA and LAMA can be administered using separate inhalers or by a single inhaler (fixed-dose LAMA/ LABA). The choice of the optimal dual bronchodilator should depend on individual patient's needs and abilities.

- Patient on a LAMA or LABA monotherapy, with persistent dyspnoea or decline of lung function despite treatment, should step up to dual therapy. In case of dual therapy intolerance or if serious side effects occur, de-escalation to LAMA or LABA monotherapy can be considered. In such cases, a strict monitoring of patient is necessary and de-escalation is possible only if no worsening of symptoms, lung function decline and/or exacerbations occur.

\section{Short-acting bronchodilators}

Current opinions: Similarly to LABA and LAMA, short-acting bronchodilators include Short-ActingMuscarinic Antagonists (SAMA) with an anti-cholinergic effect (ipratropium bromide), and Short-Acting Beta - $^{-}$ Agonists (SABA): salbutamol, fenoterol and terbutaline. Both SAMA and SABA improve $\mathrm{FEV}_{1}$, symptoms and exercise tolerance. Combined (fixed-dose) SAMA/SABA treatment is more effective in improving $\mathrm{FEV}_{1}$ and symptoms compared to each monocomponent alone.

\section{Treatment recommendations of the expert group:}

- Short-acting bronchodilators should be used as an 'asneeded' treatment for occasional symptoms' relief. In most cases, they should not be used as regular treatment. SABA or/and SAMA can be added to basic treatment regardless of disease severity or COPD phenotype.

- Short-acting bronchodilators can be used as single therapy in patients without persistent symptoms, i.e., with $\mathrm{FEV}_{1} \geq 80 \%$, mMRC 0 and $\mathrm{CAT}<10$, who do not require regular treatment by long-acting bronchodilators.

\section{Pulmonary rehabilitation}

Current opinions: Pulmonary rehabilitation is an important part of standard non-pharmacological treatment, which includes patient education, physiotherapy, occupational therapy (focused on activities of daily living - ADL), nutritional and psychosocial support (Fig. 9) (ref. ${ }^{142,143}$ ). Physiotherapy consists of exercise training (endurance and strength) and techniques of respiratory physiotherapy. It is recommended that all patients with COPD 


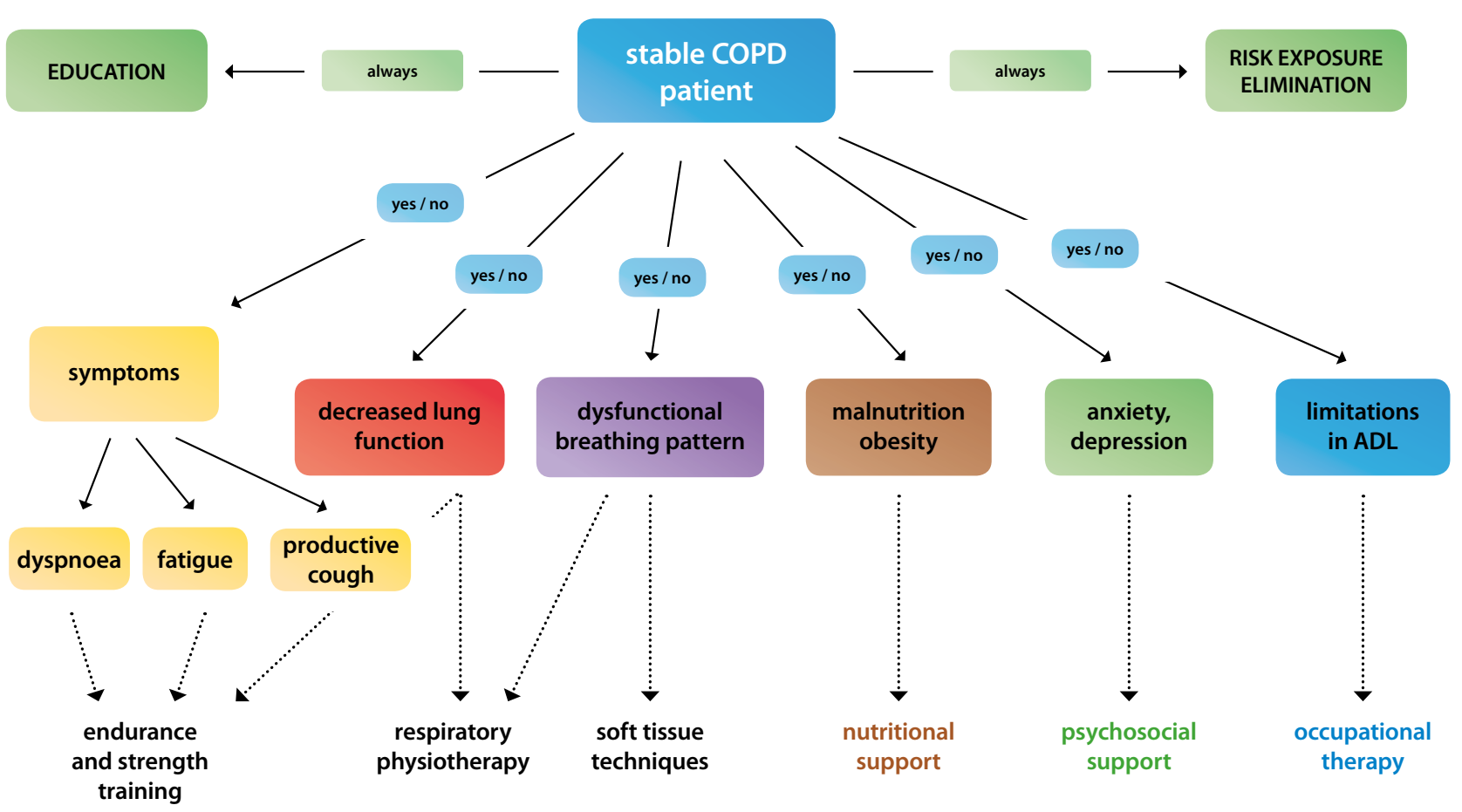

Fig. 9. Components of pulmonary rehabilitation in stable COPD.

who are symptomatic are involved in exercise training (3-5 times per week, 20-60 min, 6-8 weeks) regardless of lung function $^{144,145}$. Training sessions should be supervised by a physiotherapist at least twice a week and the training sessions (1-3 times per week) can be performed either at the patient's home or at a community rehabilitation centre ${ }^{63}$. The respiratory physiotherapy techniques include reeducation of the breathing pattern, techniques of enhancing chest expansion, airway clearance techniques and ventilatory muscle training. It is very important to add other physiotherapeutic techniques to pulmonary rehabilitation treatment, if balance disorders, low back pain or stress incontinence is present (Fig. 10). These problems are more often present in patients with COPD compared to those who do not have this disease ${ }^{146-149}$.

\section{Treatment recommendation of the expert group:}

- Pulmonary rehabilitation should be considered in each patient with symptomatic COPD regardless of disease severity or COPD phenotype.

\section{Inhalation training}

Current opinions: Inhaled medications are the cornerstone of COPD pharmacotherapy. Several types of inhalers are currently authorized and used in the treatment of COPD in the Czech Republic. The group of pressurized metered dose inhalers (pMDI group) included three types of inhalers: traditional pMDIs (aerosol), Easi-Breathe and Respimat (soft mist inhaler, SMI). They require slow and deep breathing in for at least 4 seconds and they are the method of choice for patients with low inspiratory flow. The dry powder inhalers (DPI group) comprise several types of inhalers: Handihaler, Aerolizer, Breezhaler,
Diskus, Turbuhaler, Ellipta, Genuair, Twisthaler, Easyhaler or Spiromax ${ }^{150-152}$.

Inhalator misuse is frequently observed among COPD individuals. The majority of COPD patients make mistakes, especially in the case of multiple inhalators in one patient. The inhaler technique should be checked (at least) annually by a pulmonary physician, physiotherapist, and/or respiratory nurse specialist.

Personalized training focused on all detected errors should be done subsequently by the same staff using the same instrument (Five Steps Assessment). Five Steps Assessment is available for free use at https://www.fnhk. cz/plic/aplikace-inhalacnich-leku-edukacni-videa/englishversions (animated version for patients) and the version for health-care professionals in an article by Vytrisalova et al. (Table 3 ) (ref. ${ }^{150}$ ).

\section{Treatment recommendations of the expert group:}

- We propose the use of a previously validated and published unique novel scoring instrument - Five Steps Assessment ${ }^{150}$.

\section{Vaccination}

Current opinions: Influenza vaccination prevents influenza and reduces the risk of exacerbation and death in COPD patients. Pneumococcal vaccination is effective for prevention of community acquired pneumonia and invasive pneumococcal disease. Pertussis and diphtheria vaccine can also be considered. ${ }^{1}$

\section{Treatment recommendations of the expert group:}

- Influenza and COVID-19 vaccination is recommended in patients with COPD, particularly in the elderly. 


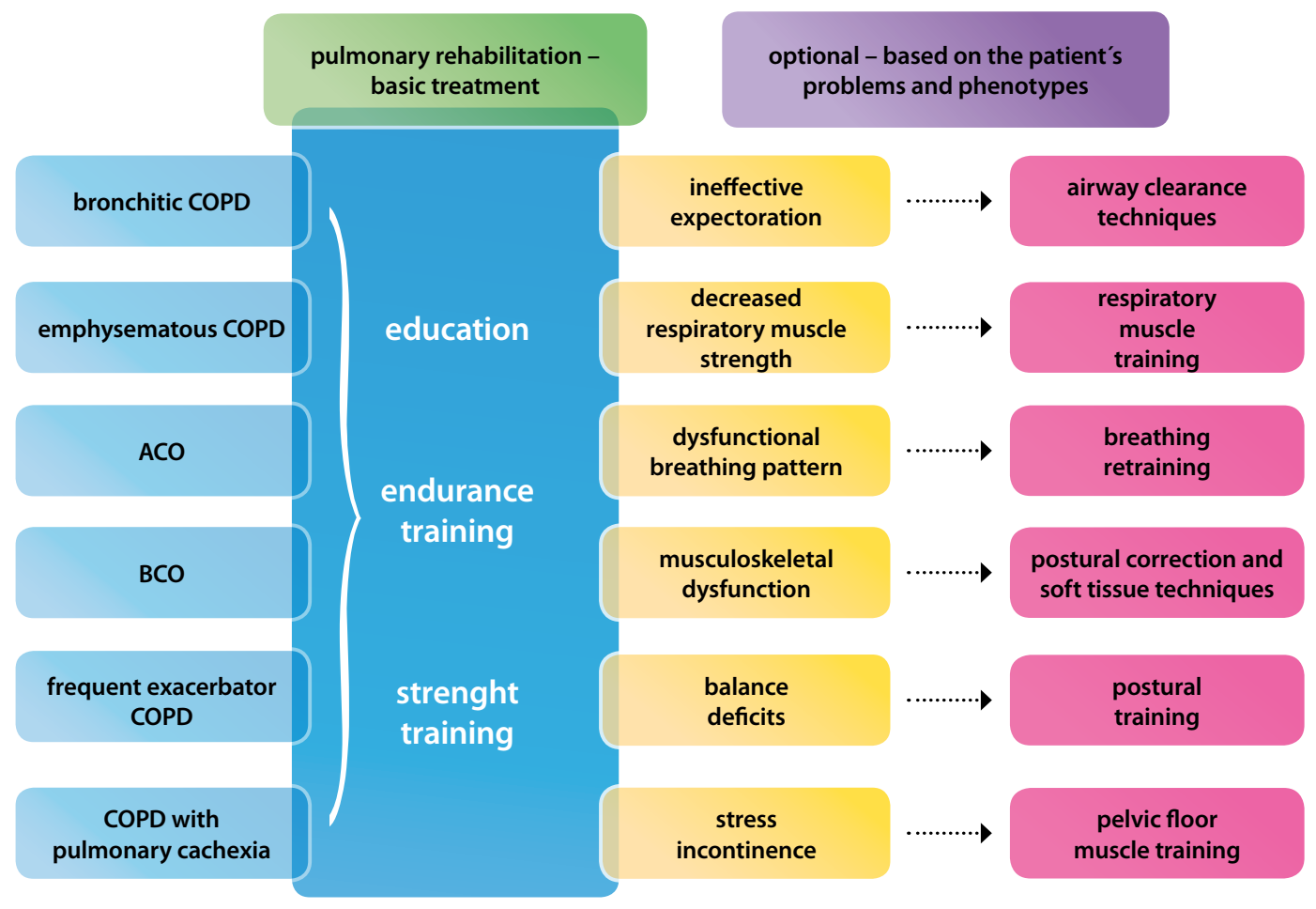

Legend: COPD - chronic obstructive pulmonary disease; ACO - asthma/COPD overlap; BCO - bronchiectases and COPD overlap

Fig. 10. Phenotypically targeted physiotherapy.

- Pneumococcal vaccination is recommended for all patients older than 65 years and for younger COPD patients with more impaired lung function and/or with comorbidities, especially cardiovascular diseases ${ }^{1,153}$.

\section{Appropriate nutrition}

Current opinions: Malnutrition is an important and complex problem associated with COPD. The exact causal links between malnutrition and COPD are difficult to establish. Malnutrition can be the consequence of COPD severity, systemic inflammation, hypoxia and alterations of metabolism. On the other hand, malnutrition can result in respiratory muscle wasting and other features of COPD. Risk of malnutrition is estimated at $30-60 \%$ in hospitalized patients ${ }^{154}$. Basic assessment of nutritional status can be provided by Body Mass Index (BMI) and Fat-Free Mass Index (FFMI) assessment. FFMI can be measured by skinfold calipers, densitometry or with the use of bioelectric impedance. Dual-energy X-ray absorptiometry (DEXA) is appropriate for combined screening of osteoporosis, fat-free mass (FFM) and fat mass. Patients with COPD and lower BMI have higher mortality risk than patients with slightly higher BMI. The prevalence of underweight in COPD increases with disease severity and is associated with the presence of emphysema. Low FFMI (less than 10\%), irrespective of BMI and fat mass, is associated with higher mortality ${ }^{155}$. Sarcopenia is characterised by low Skeletal Muscle Index (SMI) and leads to skeletal muscle weakness, particularly in older and/or overweight patients. Skeletal muscle index can be assessed by DEXA, magnetic resonance imaging and can be estimated by anthropometry including skinfold calipers measurement ${ }^{156,157}$.

Patients with COPD express various nutritional phenotypes associated with different clinical outcomes. Patients with obesity (BMI $30-35 \mathrm{~kg} / \mathrm{m}^{2}$ ) have increased cardiovascular risk, patients with morbid obesity (BMI $>35 \mathrm{~kg} / \mathrm{m}^{2}$ ) and with sarcopenic obesity (BMI 30-35 kg/ $\mathrm{m}^{2}$ and SMI <2) furthermore have impaired physical performance. Patients with sarcopenia $(\mathrm{SMI}<2)$, cachexia (FFMI $<16 \mathrm{~kg} / \mathrm{m}^{2}$ in males or FFMI $<15 \mathrm{~kg} / \mathrm{m}^{2}$ in females) have impaired physical performance and increased mortality risk. Furthermore, malnutrition is associated with loss of mineral density, fat loss, muscle loss, or conversely with adiposity and obesity ${ }^{155}$.

This position paper defines the specific „pulmonary cachexia phenotype" of COPD, defined as cachexia in patients with advanced COPD inexplicable by other causes. Pulmonary cachexia phenotype incorporates patients with COPD and body mass loss, fat loss, muscle loss and/or loss of mineral density. Pulmonary cachexia phenotype is considered an independent risk factor of mortality in COPD patients ${ }^{158}$.

Dietary management includes several therapeutic interventions. Patients with pulmonary cachexia should have nutritional supplementation. The diet should contain sufficient energetic value, be rich in proteins and be eaten in several small portions split throughout the whole day. The quality of fats should be considered. Oral nutritional supplements can be used if normal food and drink is insufficient for nutritional requirements. Counselling with a dietary specialist can be beneficial. Nutritional supple- 
Table 3. Correct application technique (Five Steps Assessment system) used to initial education and regular check-up (ref. ${ }^{150}$ ).

5 easy universal steps to correct application technique include:

$1^{\text {st }}$ step: remove the mouthpiece cover from inhaler (aerosol), turn the clear base until it clicks (soft mist inhaler) or another type of initial inhaler activation (more in video - see bellow)

$2^{\text {nd }}$ step: prepare dose of drug (for example insert a capsule into chamber, press the button, etc.) and hold device in the correct position (some of new inhalers have associated $1^{\text {st }}$ step and $2^{\text {nd }}$ step together)

$3^{\text {rd }}$ step: breath in and out and finally full and slow exhalation (exhale slowly all the air from the chest)

$4^{\text {th }}$ step: inhale the drug (slowly + smoothly during 4-5 seconds in case of pressurized metered dose inhaler or soft mist inhaler, quickly in dry powder inhalers)

$5^{\text {th }}$ step: take your inhaler device out of your mouth and hold your breath for several seconds and then breathe out slowly

Educational video available at: https://www.fnhk.cz/plic/aplikace-inhalacnich-leku-edukacni-videa/english-versions

mentation should be complemented by pulmonary rehabilitation programme including exercise training. Because of reported vitamin D deficiency and insufficient intake of vitamins with antioxidant capacity (vitamins $A, C$ and $E$ ) in COPD, supplementation of vitamin D and other vitamins should be considered ${ }^{155}$. A three-month intervention combining nutritional support, pulmonary rehabilitation and oral administration of testosterone in malnourished patients with chronic respiratory failure on LTOT has been reported previously ${ }^{159}$. This multimodal intervention resulted in increased BMI and FFMI and was associated with better muscle functioning, higher quality of life and increased rate of 15-month survival ${ }^{159}$.

\section{Treatment recommendations of the expert group:}

- Not only lower BMI, but also sarcopenia and other features of malnutrition should be sought after.

- Nutritional supplementation combined with pulmonary rehabilitation and further modalities should be used in cachectic COPD patients.

- On the other hand, adiposity should be managed by controlled weight reduction, particularly if the adiposity has clinical relevance.

\section{Education}

Current opinions: Topics of education include smoking cessation, correct inhalation technique, early recognition of exacerbation, treatment adherence, nutrition, physical activity, correct decision-making and others ${ }^{1,160}$. Education can be a component of pulmonary rehabilitation. Patients instructed about the nature of COPD and the implications of therapy can better understand, recognize, and treat the symptoms of their disease. Longer-lasting selfmanagement strategies are recommended for clinical practice rather than brief interventions ${ }^{161}$.

\section{Treatment recommendation of the expert group:}

- All patients should receive adequate education to improve COPD self-management.

\section{Psychological and social support}

Current opinions: Severe COPD is a risk factor for the development of anxiety and depression. Patients with depression are more likely smokers and find smoking cessation more difficult. On the other hand, smokers are more likely to be depressed, that may be the result of nicotinic acetylcholine receptors' activation ${ }^{162}$. Furthemore, patients with severe COPD and dyspnea often reduce their physical activity, leading to progressive decondition. Depression and decondition may result in decreased participation in social activities, often including sexual activity. Pulmonary rehabilitation improves depression and should be used as first-line treatment of depression.

\section{Treatment recommendations of the expert group:}

- If necessary, psychological counselling and/or psychological therapies and/or pharmacotherapy should be used.

- Psychological counselling can also be beneficial as part of smoking cessation efforts.

\subsection{PHENOTYPE-SPECIFIC TREATMENT}

Patients with an expressed clinical phenotype should receive adequate phenotype-specific treatment. Patient with COPD can have none, one or multiple concurrent clinical phenotypes, that can overlap. Clinical phenotypes in this concept can be understood as treatable traits. Phenotype-specific treatment is assigned to each clinical phenotype. Patients with an overlap of $\geq 2$ clinical phenotypes should receive combined treatment targeted on all present phenotypic labels.

\subsubsection{FREQUENT EXACERBATOR PHENOTYPE}

Patients with frequent exacerbations ( $\geq 2$ during last year) despite optimal bronchodilator treatment should receive inhaled corticosteroids, phosphodiesterase-4 inhibitors, mucoactive drugs, selected antibiotics or combination of these drug regimens.

\section{Inhaled corticosteroids (ICS)}

Current opinions: ICS monotherapy does not reduce mortality and has no effect on lung function decline ${ }^{132,163}$. 
ICS in combination with bronchodilators reduced the exacerbation rate, particularly in patients with previous history of exacerbations ${ }^{132}$. The effect of ICS on reducing exacerbations is higher in patients with higher blood eosinophil count and seems to be lower in patients with lower blood eosinophil count ${ }^{164,165}$.

Chronic use of ICS in COPD can be associated with adverse effects, particularly pneumonia, but also oral candidiasis, dysphonia, hematomas, skin bruising and reduction in bone mineral density. Greater risk of pneumonia has been found in patients treated by fluticasone furoate and in current smokers, patients with lower BMI and previous history of pneumonia. Withdrawal of ICS in low risk COPD patients was not associated with increase in exacerbation rate ${ }^{166}$.

Withdrawal of inhaled corticosteroids in COPD patients using triple therapy (ICS+LABA+LAMA) did not result in higher risk of exacerbations and led only to a small decrease in lung function, regardless of exacerbation history ${ }^{167,168}$. However, patients without an exacerbation history and with a blood eosinophil count $\geq 300$ cells/ $\mu \mathrm{L}$ experienced increased risk of exacerbations after ICS withdrawal ${ }^{168}$. A recommendation regarding ICS withdrawal is described in a recent European Respiratory Society guideline ${ }^{169}$.

\section{Treatment recommendations of the expert group:}

- ICS should be used in patients with frequent exacerbations and higher blood eosinophil count in the peripheral blood, either in stable phase or during COPD exacerbation.

- ICS should also be used in patients with frequent exacerbations and asthma-COPD overlap.

- ICS should be used in combination with longacting bronchodilator therapy (i.e., added to basic treatment), usually as combination ICS+LABA or ICS+LABA+LAMA. ICS monotherapy is not recommended.

- ICS should be used with precaution and treatment should be reconsidered in patients with frequent exacerbations and lower blood eosinophil count, prior history of pneumonia and lower BMI, especially in patients with emphysematic and/or cachectic phenotype.

- In patients with low exacerbation rate (0-1 exacerbation/last year) with lower blood eosinophil count in peripheral blood, withdrawal of ICS may be considered.

- Cut-off value for high blood eosinophil count in peripheral blood is $\geq 300$ cells $/ \mu \mathrm{L}$, cut-off value for low blood eosinophil count is $<100$ cells $/ \mu \mathrm{L}$. Blood eosinophil count between 100 and 300 cells $/ \mu \mathrm{L}$ is considered grey zone; in these patients, blood eosinophil count assessement should be repeated and individual risks and benefits regarding ICS use should be considered.

\section{Phosphodiesterase-4 inhibitors (PDE4 inhibitors)}

Current opinions: Roflumilast is a once daily oral anti-inflammatory drug that reduces neutrophilic inflammation in the airways due to inhibition of intracellular
cAMP degradation and subsequent effect on inflammatory cytokines and mediators ${ }^{170}$. Roflumilast reduces exacerbation rates in patients with severe and very severe COPD with chronic cough and sputum production, and with history of exacerbations ${ }^{171}$. Despite roflumilast has no direct bronchodilator activity, an add-on to LABA or LAMA improves lung function more than bronchodilators alone ${ }^{171,172}$. Roflumilast reduces exacerbations also in patients with chronic bronchitis ${ }^{173}$. Roflumilast can affect different types and isoforms of the PDE4 family of enzymes ${ }^{170,174}$. Therefore, roflumilast has more adverse events ${ }^{170}$, the most common including diarrhoea, nausea, weight loss, sleep disturbance, headache, loss of appetite or impairment of preexisting depression. Adverse events ussually appear at roflumilast treatment initiation and may result in treatment discontinuation. On the other hand, adverse events can sometimes be prevented through intermittent administration of the drug at treatment initiation.

\section{Treatment recommendations of the expert group:}

- Roflumilast can be used in patients with frequent exacerbations and bronchitic phenotype. Particularly, roflumilast should be considered in patients with combination of these two phenotypes and severe airflow limitation and/or exacerbation history despite ICS+LABA treatment.

- Lower blood eosinophil count and/or higher neutrophilia can support the use of roflumilast in these patients, especially if a history of pneumonia is present.

- Roflumilast should not be used concurrently with theophylline and in patients with depression or pulmonary cachexia.

- In patients with adverse events, intermittent administration of the drug at treatment initiation can be considered.

\section{Mucoactive drugs containing thiol group}

Current opinions: Erdosteine and $\mathrm{N}$-acetylcysteine are thiol-based mucoactive drugs. Both substances have mucomodulatory and antioxidant effect. Erdosteine reduces both the rate and duration of exacerbations in patients with COPD (ref. ${ }^{175}$ ). The most pronounced effect of erdosteine on exacerbation rate and duration was observed in patients with milder airflow obstruction. Erdosteine's effects on exacerbations are not substantially influenced by blood eosinophil count ${ }^{176}$. High doses of $\mathrm{N}$-acetylcysteine reduced the number of COPD exacerbations per patientyear, but not the proportion of patients who remained exacerbation-free ${ }^{6}$. Mucolytics are well tolerated and safe drugs with rare adverse events.

\section{Treatment recommendations of the expert group:}

- Long-term treatment with thiol-based mucoactive drugs (erdosteine or $\mathrm{N}$-acetylcysteine) should be used in patients with frequent exacerbations, $\mathrm{BCO}$ and bronchitic phenotype.

- Furthermore, they can be used as add-on therapy in patients with exacerbation phenotype without chronic 
bronchitis, particularly in patients with early stages of COPD with less severe airway obstruction.

- Combination with other phenotype-specific drugs in frequent exacerbators (ICS, roflumilast) is possible and may be beneficial.

\section{Long-term antibiotic treatment}

Current opinions: Long-term azithromycin therapy significantly reduced the number of exacerbations ${ }^{177}$, but was associated with increased bacterial resistance to macrolides and with adverse events, such as hearing loss and QT-interval prolongantion ${ }^{178}$. Similarly, intermittent treatment with fluoroquinolones (moxifloxacin $400 \mathrm{mg}$ daily for 5 days every 2 months for 1 year) significantly reduced exacerbation rates in patients with purulent sputum production, but similarly was associated with bacterial resistance and with adverse events. The Spanish guidelines recommend long-term use of macrolides in patients with severe COPD and with at least 3 exacerbations in the previous year. The treatment should be administered in reference centers due to the need of strict monitoring of adverse effects and developments of antibiotic resistance ${ }^{3}$.

\section{Treatment recommendations of the expert group:}

- Long-term antibiotic treatment (macrolides, fluoroquinolones) is reserved as special treatment for severe or very severe COPD patients with frequent bacterial exacerbations despite all usual therapy.

- Long-term antibiotic treatment may also be considered in COPD patients with frequent exacerbations and bronchiectases.

- The treatment should be administered in tertiary care centers and with precaution to all possible adverse effects and microbial resistances development.

\subsubsection{BRONCHITIC PHENOTYPE}

\section{Mucoactive drugs containing thiol group}

Current opinions: Basic characteristics of erdosteine and $\mathrm{N}$-acetylcysteine are listed in the section describing treatment of frequent exacerbation phenotype. Above that, erdosteine and other thiol-based mucoactive drugs have antioxidant and antiinflammatory effect that improves symptoms of chronic bronchitis ${ }^{179}$. Chronic bronchitis phenotype is associated with higher risk of exacerbation and mortality ${ }^{180}$. Therefore, reduction of exacerbations with thiol-based mucoactive drugs treatment is beneficial $^{175,181}$.

\section{Treatment recommendations of the expert group:}

- Long-term treatment with thiol-based mucoactive drugs should be used in patients with bronchitic phenotype, with or without history of exacerbation.

- Mucoactive drug therapy may be beneficial for patients with mild or moderate COPD as an early intervention approach ${ }^{182}$.

- The treatment can be adjusted to symptoms of chronic bronchitis (for example, erdostein twice daily during marked sputum production, or in contrast, interruption of mucoactive treatment when there is no cough and sputum).

\section{Phosphodiesterase-4 inhibitors (PDE4 inhibitors)}

Current opinions: General characteristics of roflumilast are presented in the section describing the treatment of frequent exacerbation phenotype. Anti-inflammatory effect of roflumilast on neutrophilic inflammation in the airways and beneficial effect on lung function can be a rationale for roflumilast use in patients with bronchitic phenotype, especially if frequent bacterial exacerbations are present ${ }^{172}$.

\section{Treatment recommendations of the expert group:}

- Roflumilast can be used in patients with bronchitic phenotype of COPD, especially in patients with more severe stages of the disease, with a history of bacterial exacerbation or pneumonia.

- Higher neutrophils count (in airways and/or peripheral blood) supports the use of roflumilast.

- Roflumilast can be used in combination with thiolbased mucoactive drugs in patients with bronchitic phenotype.

- Roflumilast should be avoided in patients with pulmonary cachexia phenotype. Further limitations of roflumilast are presented in the section describing treatment of the frequent exacerbation phenotype.

\section{Pulmonary rehabilitation}

Current opinions: Airway clearance techniques improve mucus clearance and reduce airways inflammation.

\section{Treatment recommendation of the expert group:}

- Pulmonary rehabilitation and regular aerobic exercise should be routine part of treatment in patients with bronchitic phenotype as a tool to reduce symptoms and exacerbation rates.

\subsubsection{EMPHYSEMATOUS PHENOTYPE}

The main goals of therapy in patients with pulmonary emphysema are improvements of dyspnoea, respiratory mechanics, respiratory muscle strength, and reversal of macroscopic structural changes with the use of volume reduction procedures.

\section{Methylxanthines}

Current opinions: Theophylline is the only methylxanthine available for use in the Czech Republic. Theophylline improves dyspnea, especially when added to LABA (ref. ${ }^{183,184}$ ). Theophylline has a modest bronchodilator effect, enhanced in combination with LABA (ref. ${ }^{184,185}$ ). Theophylline is able to increase diaphragmatic muscle strength, reduce gas trapping and improve the mucociliary clearance ${ }^{185}$. Although the role of theophylline in the general COPD population is considered controversial ${ }^{1}$, the mentioned features of theophylline allow to 
expect its benefit in management of patients with emphysema. The role of theophylline in prevention of exacerbations has not been documented ${ }^{186}$. Theophylline has a narrow therapeutic range and frequent adverse effects. Theophylline is metabolized via cytochrome P450 1A2, therefore an interaction with other drugs may occur.

\section{Treatment recommendations of the expert group:}

- Theophylline should be used as phenotype-specific treatment in emphysematous phenotype of COPD.

- During long-term treatment, patient should be carefully monitored by a physician, including monitoring of adverse effects, plasma concentrations of theophylline and possible interactions with other drugs.

\section{Pulmonary rehabilitation}

\section{Treatment recommendation of the expert group:}

- Respiratory muscle training can improve the descreased respiratory muscle strength and should be used in patients with emphysematous phenotype.

\section{Non-pharmacological treatment}

Current opinions: Non-pharmacological therapeutic interventions in patients with advanced pulmonary emphysema include bronchoscopic lung volume reduction (BLVR) and lung volume reduction surgery (LVRS).
BLVR procedures include endobronchial valves (EBV) and coils placement. Both valves and coils can be used in patients with severe hyperinflation, severe emphysema and absent airway disease (asthma, chronic bronchitis, bronchiectases) (Table 4) (ref. ${ }^{187}$ ).

Targeted implantation of endobronchial one-way valves into the airways of an isolated emphysematous lobe appears to be one of the most promising innovations ${ }^{188-190}$. After a valve placement, $\mathrm{FEV}$, and walking distance (6MWT) should improve. The efficacy of valve placement depends on the presence of interlobar collateral ventilation. Major complications following a valve placement include COPD exacerbations, hemoptysis, valve migration, and pneumothorax ${ }^{187,191}$.

Endobronchial coils can be used in patients with heterogeneous as well as homogeneous emphysema, independently on interlobar collateral ventilation ${ }^{187}$. The implantation of coils is usually permanent, only one or two coils can be removed. After a coil treatment, FEV, and walking distance (6MWT) should improve. Reported complications of the coil procedure include COPD exacerbations, hemoptysis, transient chest pain, pneumonia, pneumothorax, and noninfectious coil-associated opacities $^{187}$.

Further endoscopic lung volume reduction procedures include bronchoscopic thermal vapour ablation, biologi-

Table 4. Eligibility criteria for EBV, LVRS or bullectomy.

\begin{tabular}{|c|c|c|c|}
\hline & EBV & LVRS & BULLECTOMY \\
\hline \multirow{3}{*}{$\begin{array}{l}\text { Clinical } \\
\text { characteristic }\end{array}$} & Dyspnoea (mMRC score $\geq 2$ ) & Dyspnoea (mMRC score $\geq 2$ ) & Dyspnoea (mMRC score $\geq 2$ ) \\
\hline & & Low fitness & \\
\hline & Stable prior to procedure & Stable prior to procedure & Stable prior to procedure \\
\hline \multirow[t]{2}{*}{ Chest HRCT } & $\begin{array}{l}\text { Heterogeneous emphysema } \\
\text { (upper or lower lobe } \\
\text { predominance) }\end{array}$ & $\begin{array}{l}\text { Heterogeneous emphysema (upper lobe } \\
\text { predominance) }\end{array}$ & $\begin{array}{l}\text { Impairment of }>1 / 3 \text { of affected } \\
\text { hemithorax }\end{array}$ \\
\hline & $\begin{array}{l}\text { No collateral ventilation in the } \\
\text { targeted lobe }\end{array}$ & & $\begin{array}{l}\text { Radiographic evidence of } \\
\text { compressed lung }\end{array}$ \\
\hline RV & $>175 \%$ of predicted value & $>175 \%$ of predicted value & \\
\hline $\mathrm{FEV}_{1}$ & $15-50 \%$ of predicted value & $15-50 \%$ of predicted value & \\
\hline TLco (DLco) & $>15-20 \%$ of predicted value & $>20 \%$ of predcited value & \\
\hline $\mathrm{PaCO}_{2}$ & No hypercapnia & No hypercapnia & No hypercapnia \\
\hline \multirow[t]{2}{*}{ History } & $\begin{array}{l}\text { No severe pulmonary } \\
\text { comorbidity }\end{array}$ & No severe pulmonary comorbidity & $\begin{array}{l}\text { No severe pulmonary } \\
\text { comorbidity }\end{array}$ \\
\hline & $\begin{array}{l}\text { Able to undergo sedation or } \\
\text { general anesthesia }\end{array}$ & Able to undergo general anesthesia & $\begin{array}{l}\text { Able to undergo general } \\
\text { anesthesia }\end{array}$ \\
\hline Smoking & Smoking cessation & Smoking cessation & Smoking cessation \\
\hline
\end{tabular}

(ref. ${ }^{187-190,194,196-199}$ ).

Abbreviations: EBV - endobronchial valve, FEV1 - forced expiratory volume in 1 second, HRCT - high resolution computer tomography,

LVRS - lung volume reduction surgery, RV - residual volume, TLco - tranferfactor. 
cal lung volume reduction (using the lung sealant system), or airway bypass stent ${ }^{187,191-193}$.

Surgical methods (LVRS or bullectomy) are less frequently used compared to BLVR. LVRS should be considered in patients with upper-lobe predominant distribution of emphysema. LVRS in well-selected patients improved symptoms, dynamic hyperinflation, cardiopulmonary mechanics, exercise capacity, exacerbation rate and mortality ${ }^{191,194-196}$.

Plasmatic levels of alpha-1 antitrypsin should be examined in each patient with COPD, especially with emphysematous phenotype in order to identify patients with severe forms of alpha-1 antitrypsin deficiency ${ }^{47}$.

\section{Treatment recommendations of the expert group:}

- In patients with the large bullous type of emphysema, endoscopic or surgical volume reduction procedures should be considered in specialized tertiary care centers.

- Targeted implantation of endobronchial one-way valves (EBV) should be considered in patients with isolated emphysematous lobes.

- LVRS or bullectomy should be considered in patients with predominant upper-lobe distribution of emphysema, and low pre-procedure exercise capacity.

- Patients with alpha-1 antitrypsin deficiency should be referred to the specialized Center for treatment of alpha-1 antitrypsin deficiency (Thomayer Hospital, Prague) to consider alpha-1 antitrypsin augmentation therapy.

\subsubsection{ASTHMA-COPD OVERLAP (ACO)}

Patients with overlap of COPD and asthma (ACO) usually have a combination of symptoms of both diseases and some degree of eosinophilic inflammation in airways. Therefore, treatment of all patients with ACO phenotype should include inhaled corticosteroid, as phenotypicalspecific treatment added to basic treatment with bronchodilators.

\section{Inhaled corticosteroids(ICS) in combination with bron- chodilators}

Current opinions: The first option of phenotype-specific treatment of ACO is combination ICS+LABA. Similarly to asthma strategies, the dose of ICS should be set to the minimum dose necessary for disease control maintenance. Triple therapy ICS+LABA+LAMA should be used, if dual combination LABA+LAMA as basic treatment is necessary and ICS as phenotype-specific treatment is added-on or if ICS+LABA as phenotype-specific treatment is insufficient to achieve satisfactory disease control.
Treatment recommendations of the expert group:

- Combination of ICS+LABA should be used in patients with ACO.

- Triple therapy ICS+LABA+LAMA should be used if dual combination LABA+LAMA as basic treatment is necessary or if only ICS+LABA combination is insufficient to achieve satisfactory disease control.

\section{Leukotriene receptor antagonists (antileukotrienes)}

Current opinions: There is no evidence supporting the use of antileukotrienes in COPD. Antileukotrienes had no effect on lung funcion decline in a non-selected COPD population $^{200}$. However, during long-term montelukast treatment in moderate-to-severe COPD patients, significant improvement of disease symptoms, reduction in ICS and inhaled bronchodilators' need as well as reduction in emergency department referrals and hospitalizations was observed, though no changes in $\mathrm{FEV}_{1}$ were recorded ${ }^{201}$. These data can a be rationale for antileukotrienes' use in selected patients with ACO.

\section{Treatment recommendation of the expert group:}

- Leukotriene receptor antagonists can be considered in patients with ACO phenotype if allergic feature of asthmatic component is present and ICS+bronchodilator combination is not sufficient to achieve satisfactory control of the disease.

\subsubsection{BRONCHIECTASES WITH COPD OVERLAP (BCO)}

\section{Mucoactive drugs containing thiol group}

Current opinions: Basic characteristics of thiol-based mucoactive drugs are presented in the section describing the treatment of frequent exacerbation phenotype. Importantly, erdosteine has an antibacterial effect due to inhibition of bacterial adhesiveness. Erdosteine also increases antibiotic concentrations in the airway mucus ${ }^{202}$. Mucoactive drugs are recommended in patients with bronchiectasis and difficult expectoration ${ }^{203}$.

\section{Treatment recommendation of the expert group:}

- Long-term erdosteine or other mucoactive drug ( $\mathrm{N}$-acetylcysteine) treatment should be used in patients with bronchiectases and COPD overlap phenotype.

\section{Phosphodiesterase-4 inhibitors (PDE4 inhibitors)}

Current opinions: General characteristics of roflumilast are presented in the section describing the treatment of frequent exacerbation phenotype. Data regarding effect of roflumilast in patients with bronchiectases or BCO are lacking. However, roflumilast inhibits neutrophilic airway inflammation in COPD and prevents exacerbations in COPD with chronic bronchitis. Neutrophils are the prominent cell type involved in pathogenesis of both bronchiectases and COPD (ref. ${ }^{204}$ ). This could be a rationale for roflumilast use in patients with COPD and bronchiectases. 
Treatment recommendations of the expert group:

- Treatment with roflumilast can be considered as complemetary treatment in patients with $\mathrm{BCO}$, especially if excessive sputum production and/or frequent exacerbations are present.

- The effect of roflumilast treatment should be evaluated and treatment with roflumilast should be continued only if it's beneficial.

- Limitations of roflumilast treatment are presented in the section describing the treatment of frequent exacerbation phenotype.

\section{Antibiotics}

Current opinions: Recent European guidelines recommend long-term treatment by inhaled antibiotics (colistin or gentamicin) as first-line treatment in patients with bronchiectases experiencing exacerbations and/or chronic Pseudomonas aeruginosa airway colonisation. The same guidelines support chronic macrolide therapy as a second-line treatment in selected patients with bronchiectases $^{203,204}$.

\section{Treatment recommendation of the expert group:}

- Chronic antibiotic treatment (or inhaled antibiotics) should follow the bronchiectases treatment guidelines, as mentioned above.

\section{Pulmonary rehabilitation}

Current opinions: Pulmonary rehabilitation improves exercise capacity and reduces exacerbation rates in patients with bronchiectases. Airway clearance techniques improve mucus clearance and airways inflammation. The ERS guidelines recommend pulmonary rehabilitation programme and regular aerobic exercise as tools to reduce exacerbation rates.

\section{Treatment recommendation of the expert group:}

- Pulmonary rehabilitation and airway clearance techniques should be routine part of treatment in patients with BCO.

\section{Other treatments}

Current opinions: There is interest in immunostimulating agents. These drugs consist of antigens of several bacterial strains and are designed to stimulate the immune response (for example Broncho-Vaxom). These agents reduced exacerbation rates in COPD patients. Novel treatments are under investigation, for example neutrophil elastase inhibitors or CXC chemokine receptor 2 antagonist CXCR2 ( ref. $^{205}$ ).

\section{Treatment recommendation of the expert group:}

- Immunostimulating agents can be considered as complemetary treatment in patients with $\mathrm{BCO}$.

\subsubsection{PHENOTYPE OF PULMONARY CACHEXIA}

COPD patients with pulmonary cachexia should receive rigorous nutritional support, pulmonary rehabilitation and psychosocial support ${ }^{206}$. Since pulmonary cachexia more frequently occurs with advanced-stage COPD, treatment of respiratory insufficiency and supportive treatment may be necessary. If patients with pulmonary cachexia experience frequent bacterial exacerbations and/or bronchiectases, long-term antibiotic treatment should be considered. Roflumilast treatment should be avoided.

\section{Treatment recommendations of the expert group:}

- Nutritional support, complex pulmonary rehabilitation and supportive care should be used to revert poor prognosis of cachectic patients.

- Long-term antibiotic treatment is recommended if frequent bacterial exacerbations and/or bronchiectases are co-present with cachexia.

\subsubsection{MULTIPLE PHENOTYPES' CO-PRESENCE}

If more than one clinical phenotype is present, treatment strategy should follow the expression of each clinical phenotype separately. In such patients, multicomponental therapeutic regimens are required, often resulting in a fully individualized care.

\subsection{TREATMENT OF RESPIRATORY FAILURE, LUNG TRANSPLANTATION AND PALLIATIVE CARE (END-OF LIFE CARE)}

\section{Long-term oxygen therapy}

Current opinions: Long-term oxygen therapy (LTOT) for patients with COPD and chronic respiratory failure improves symptoms, exercise capacity, cognitive function, quality of life and hospitalisation rates. The effect of LTOT on mortality risk remains controversial ${ }^{207,208}$. Criteria for LTOT in the Czech Republic are: respiratory failure with resting $\mathrm{p}_{\mathrm{a}} \mathrm{O}_{2}<7.3 \mathrm{kPa}$, or $\mathrm{p}_{\mathrm{a}} \mathrm{O}_{2}$ between 7.3 and $8.0 \mathrm{kPa}$ and at least one of four further criteria, i.e., pulmonary hypertension or secondary polyglobulia or arterial oxygen desaturation less than $90 \%$ during at least $30 \%$ time of sleep or exercise-induced arterial oxygen desaturation. Smoking abstinence is necessary. Possible sources of oxygen for LTOT include oxygen concentrator, portable oxygen concentrator or liquid oxygen. Oxygen should be administered for $\geq 16$ h daily. Further indications for oxygen supplementation in COPD include nocturnal hypoxemia, oxygen administration during exercise or during airflight. If hypoxemia with hypercapnia is present, non-invasive ventilation should be considered ${ }^{209}$.

\section{Treatment recommendation of the expert group:}

- LTOT should be considered in severe chronic hypoxemia $\left(\mathrm{p}_{\mathrm{a}} \mathrm{O}_{2}<7.3 \mathrm{kPa}\right)$ or in moderate hypoxemia coinciding with pulmonary hypertension, polyglobulia, 
oxygen desaturation $<90 \%$ during at least $30 \%$ time of sleep or exercise-induced arterial oxygen desaturation.

\section{Domiciliary non-invasive ventilation}

Current opinions: The use of long-term domiciliary non-invasive ventilation therapy (dNIV) is the method of choice in stable COPD patients with chronic hypercapnic respiratory failure (indication criteria are listed in Table 5), most frequently in patients with COPD stage/group 4/D. In many cases, there is need to combine dNIV and long-term oxygen therapy (LTOT).

Best clinical outcomes were observed with dNIV preset to achieve the physiological goal of maximal $\mathrm{PaCO}_{2}$ reduction ${ }^{210,211}$. This dNIV concept, the so-called highintensity NIV (HINIV), commonly uses high inspiratory pressures (20-40 mbar, according to patient's tolerance) at the respiratory rate that approaches the spontaneous rate of the patient. Expiratory pressure is usually preset low (3-6 mbar), unless there is need to compensate obstructive sleep apnea (OSA) (ref. ${ }^{212,213}$ ). OSA is a common condition and increases mortality in COPD patients ${ }^{214}$. We therefore recommend polygraphy prior to dNIV initiation $^{214}$

In stable hypercapnic COPD patients HINIV treatment resulted in lower mortality risk, improvement in blood gases, lung function and quality of life (QoL) and enhanced effect of pulmonary rehabilitation ${ }^{210,212,215-217}$. While dNIV has no proven benefit in patients after acute hypercapnic COPD exacerbation when hypercapnia resolves $^{218}$, dNIV added to LTOT reduced risk of readmission or death when hypercapnia $\left(\mathrm{PaCO}_{2}>7.0 \mathrm{kPa}\right)$ persisted for at least 14 days after resolution of acute respiratory acidosis ${ }^{219}$.

\section{Treatment recommendation of the expert group:}

- dNIV should be considered in hypercapnic COPD individuals; exact indications are summarized in Table 5.

\section{Lung transplantation}

Current opinions: COPD is one of the most frequent reasons for lung transplantation. Lung transplantation improves health status and functional capacity ${ }^{1}$. The majority of lung transplants in patients with COPD are bilateral lung transplantations. Of 19,135 lung transplantations for COPD performed worldwide between January 1992 and June 2017, the median survival was 7 years in patients receiving bilateral lung transplant and 5 years in patients receiving single lung transplant, respectively ${ }^{220}$.

Lung transplantation should be considered in patients with very severe COPD with failing conservative treatment. In the Czech Republic, patients with COPD should be referred to the Czech Lung Transplantation Center once fulfilling these criteria: (1) progression of COPD despite maximal treatment including pharmacotherapy, pulmonary rehabilitation and LTOT, (2) BODE score $\geq 5$, (3) $\mathrm{PaCO}_{2}>6.6 \mathrm{kPa}$ and/or $\mathrm{PaO}_{2}<8 \mathrm{kPa}$, (4) $\mathrm{FEV}_{1}<25 \%$ of predicted values.

Contraindications for lung transplantation include history of malignancy in the last 5 years, poorly controlled diasease/dysfunction of another major organ system (e.g. heart, liver, kidney, brain), ischemic heart disease not amenable to revascularization, acute instability (including but not limited to acute sepsis, myocardial infarction or liver failure), uncorrectable bleeding disorder, poorly controlled chronic infection by virulent and/or resistant microbe, active tuberculosis, significant chest wall or spinal deformity, obesity with BMI $>35 \mathrm{~kg} / \mathrm{m}^{2}$, psychiatric disorders, patient's non-adherence to treatment, patient's inadequate social support, functional limitation with inability to participate in a rehabilitation program, a history of drug abuse or dependence (e.g., alcohol, tobacco, marijuana, or other illicit substances) (ref. ${ }^{221,222}$ ).

Eligible patients are placed on the lung transplant waiting list once fulfilling at least one of the following criteria: (1) BODE score $\geq 7$, (2) $\mathrm{FEV}_{1}<15-20 \%$ of predicted values, (3) history of $\geq 3$ severe exacerbations during last year, (4) history of at least one severe exacerbation with hypercapnic respiratory failure, (5) moderate to severe pulmonary hypertension. LVRS can be performed in selected patients prior to lung transplantation.

Treatment recommendation of the expert group:

- Patients with very severe COPD eligible for a lung transplant (criteria see above) should be referred to the Czech Lung Transplantation Center, University Hospital Motol, Prague.

Table 5. Indication for use of domiciliary non-invasive ventilation in COPD patients.

dNIV is indicated for stable COPD patients in presence of at least one of the following criteria:

Symptomatic daytime hypercapnia $\left(\mathrm{PaCO}_{2} \geq 6.5 \mathrm{kPa}\right)$

Nocturnal hypercapnia $\left(\mathrm{PaCO}_{2} \geq 7.3 \mathrm{kPa}\right)^{*}$

Mild daytime hypercapnia $\left(\mathrm{PaCO}_{2} 6.0-6.5 \mathrm{kPa}\right)$ with nocturnal increase $\geq 1.3 \mathrm{kPa}$ *

Persistent hypercapnia $\left(\mathrm{PaCO}_{2}>7.0 \mathrm{kPa}\right)$ for at least 14 days after finishing acute ventilation therapy for acute respiratory acidosis

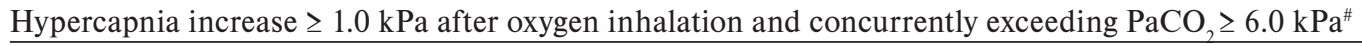

\footnotetext{
Legend:

$\mathrm{PaCO}_{2}$ - partial pressure of carbon dioxide in arterial blood

$\mathrm{kPa}$ - kiloPascal

* measured by transcutaneous capnometry (or blood gases analysis at awakening)

\# i.e., hypercapnia increase contraindicating LTOT indication
} 


\section{Palliative and end-of-life care}

Current opinions: Patients with advanced-stage (endstage) COPD should receive palliative care, that should prevent and relieve their suffering. Adequate communication or/and psychological care for patients and their families may be necessary. However, mortality risk prediction may be challenging in patients with severe COPD, since the gradual slow lung functions deterioration can be modified by acute exacerbations, often very frequent and with variable effect on both short-term and long-term outcome.

The main goal of best supportive care is achievement of sustainable quality of life for the patient and his/her family. End-of-life care should be provided to patients in final stage of the disease. Palliative and end-of-life care include various interventions, i.e., pharmacological therapy of COPD symptoms, pain, rehabilitation, oxygen therapy, non-invasive ventilation, administration of opioids, pharmacological sedation or treatment of depression and anxiety. The uncertainty regarding prognosis may play a significant role in discussions with patients and their families and can be a reason why patients with COPD are less likely to receive hospice care services ${ }^{223,224}$.

\section{Treatment recommendation of the expert group:}

- Palliative and end-of-life care including pharmacological therapy of COPD symptoms, pain, rehabilitation, oxygen therapy, non-invasive ventilation, administration of opioids, pharmacological sedation or treatment of depression and anxiety should be offered to patients in final stage of the disease, with treatment choice depending on actual clinical problems.

\subsection{TREATMENT OF COMORBIDITIES}

All relevant comorbidities should be identified and adequately treated. In general, comorbidities should be treated in usual way, regardless of coincidence with COPD. There are several comorbidities, that deserve special attention since they may strongly influence the natural course of COPD. Some comorbidities are present in COPD patients very frequently and as such, can be perceived as treatable traits of COPD. Coincidence of COPD and multiple prevalent comorbidities can also be viewed as "comorbid phenotype".

\section{Cardiovascular diseases}

Current opinions: Cardiovascular diseases (CVD) coexist with COPD very frequently due to high prevalence of both disease categories in adult and senior populations. As stated above, increased levels of circulating inflammatory mediators and acute-phase proteins are drivers not only by COPD pathogenesis, but also contributors to the development of comorbidities, including CVD, skeletal muscle dysfunction, osteoporosis, depression, cachexia, diabetes mellitus or sleep apnoea syndrome ${ }^{27-32}$.

The coexistence of COPD and CVD has a negative impact on prognosis ${ }^{60}$. CVD as a comorbidity of COPD includes chronic heart failure $(\mathrm{CHF})$, ischemic heart disease, arrhythmias, atherosclerotic peripheral vascular disease and systemic hypertension. Acute worsening/ decompensation of CVD, especially (but not limited to) $\mathrm{CHF}$, ischemic heart disease or arrhythmias, may mimic or accomplish acute exacerbation of COPD and differential diagnosis can be very difficult. Furthermore, exacerbation of COPD may result in decompensation of CVD and

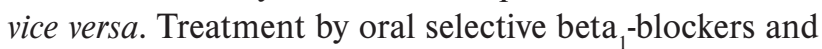
by inhaled selective beta ${ }_{2}$-agonists can be used in patients with coexisting CVD and COPD ( ref. $^{1}$ ).

\section{Treatment recommendation of the expert group:}

- CVDs are main drivers of mortality in COPD patients; therefore, careful management of these comorbidities is warranted.

\section{Gastroesophageal reflux disease (GERD)}

Current opinions: Estimated prevalence of GERD among patients with COPD ranges from $17 \%$ to $54 \%$ $\left(\right.$ ref. $^{225}$ ). Presence of GERD is associated with greater risk of acute COPD exacerbation ${ }^{225}$. It is speculated that GERD may be a driver of certain subtype of COPD exacerbations.

\section{Treatment recommendation of the expert group:}

- In patients with frequent exacerbations phenotype, GERD should be treated adequately once diagnosed.

\section{Obstructive sleep apnea (OSA)}

Current opinions: OSA is a relatively common comorbidity of COPD with similar physiological and molecular consequences, including hypoxia, systemic inflammation, CVD, pulmonary arterial hypertension and other comorbidities. OSA is rarely present in patients with emphysematous phenotype of COPD (usually associated with low $\mathrm{BMI})$. In contrast, chronic bronchitic phenotype is characterized by peripheral airway mucosal edema, bronchial hypersecretion and increased BMI, and these conditions promote easier development of OSA. Patients with overlap of COPD and OSA have worse prognosis compared to both COPD or OSA alone ${ }^{226}$.

\section{Treatment recommendation of the expert group:}

- Especially in COPD patients with bronchitic phenotype and overweight, OSA should be considered, eventually raising need for dNIV therapy.

\section{Other comorbidities}

Osteoporosis is frequently present with emphysematous phenotype and low BMI. Treatment of osteporosis should correspond to usual guidelines.

Depression and anxiety are important comorbidities associated with poorer prognosis. Therefore, psychological treatment (or even psychiatric care) and social support should be part of the basic treatment in COPD as mentioned above.

As already mentioned, lung cancer is often associated with COPD, and patients with larger degree of cigarette smoke exposure, with emphysematous phenotype or a 


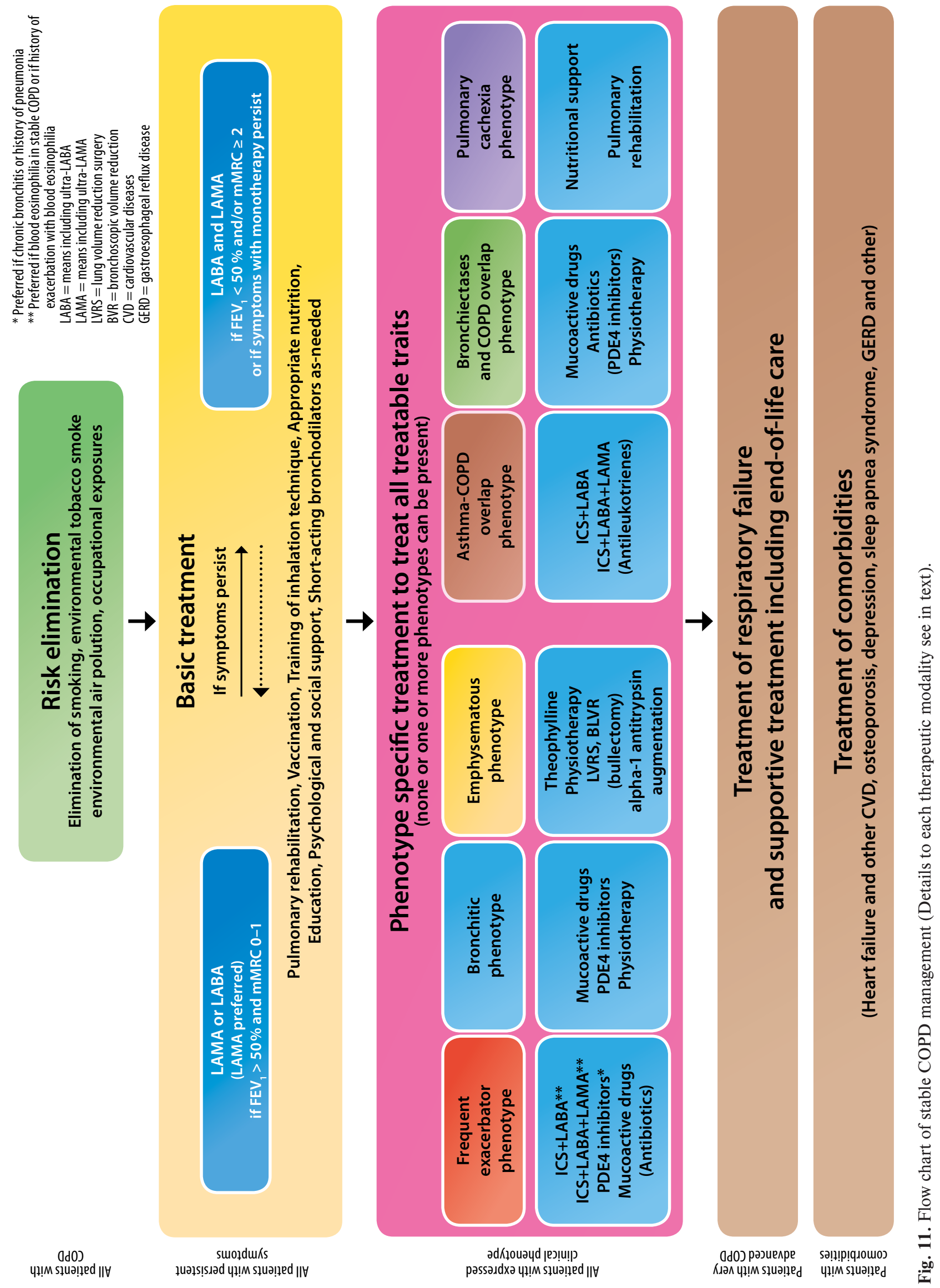


combination of emphysematous and bronchitic phenotypes express higher risk of lung cancer development ${ }^{27,34}$.

\section{FLOW CHART OF MANAGEMENT OF STABLE COPD}

After COPD is diagnosed, maximal effort to eliminate risk factors should be made and basic treatment should be started. Clinical phenotype assessment should be done as soon as possible. If at least one phenotype/treatable trait is expressed, phenotype-specific treatment should be started in accordance with each patient's individual needs.

New phenotypes can develop in each individual patient and the present phenotypes may dynamically change over time. Therefore, treatment should be re-evaluated in about one-year periods and eventually adjusted to the actual clinical appearance and circumstances. Not only therapeutic adds-on, but also treatment reduction should be considered in case the current treatment is ineffective or obsolete or when long-term control of phenotype-specific symptoms has been achieved. For example, phenotypespecific treatment should be started with new detection of clinical phenotype or, it can be reduced if manifestation of a clinical phenotype has vanished.

Various types of non-pharmacological treatment are equally important to pharmacological therapies. Above that, all relevant comorbidities should be treated. Patients with advanced COPD and respiratory insufficiency should receive appropriate specialized treatment (e.g., dNIV, LTOT, rehabilitation, psychosocial support) and patients with terminal disease should receive the best supportive/palliative treatment. Complete elaboration is presented in Fig. 11.

\section{FUTURE DIRECTIONS AND DEVELOPMENTS}

Despite notable progress and changing paradigms during the last twenty years, the integrated effort of researchers and clinicians should be made in several areas in order to improve management and prognosis of COPD (ref. ${ }^{227}$ ).

Early diagnosis in symptomatic, previously undiagnosed populations with high inhalation exposure will probably lead to modifying disease progression. Especially, early smoking cessation is a key factor in effective COPD management. Therefore, screening or early detection programs should be advocated by national and local authorities ${ }^{228-234}$. In the Czech Republic, a pivotal early detection programme has been ongoing since 2019 and the results will show if implementation in daily clinical practice will be beneficial - see above Fig. 7 ( ref. $^{235}$ ).

The concept of predictive, preventive, personalized and participatory medicine ( $\mathrm{P} 4$ medicine) for COPD patients has been discussed in recent years ${ }^{26}$. Personalized approach can better reflect the complexity and heterogeneity of COPD as it provides treatment tailored to the patient's individual needs ${ }^{26}$. Systems medicine explores disease networks at multiple levels, ranging from the molecular level, through cells, organs, to the population level ${ }^{236}$. A systems medicine approach, integrating genetic, (micro)biological, radiological, clinical, environmental and lifestyle factors in experimental and computational models may advance personalized treatment of COPD (ref. ${ }^{236}$ ).

Another important issue is to identify specific biomarkers or measures not only for early diagnosis and identification of patients responsive to specific treatments, but also for prediction of rapid lung function decline, comorbidities development, exacerbation and mortality risk ${ }^{26,237}$. Many of these points require a much deeper, integrative and more comprehensive understanding of COPD pathophysiology, natural course of the disease, its genetics and epigenetics and prenatal lung development, along with socioeconomic and environmental factors ${ }^{26}$. Currently, the most promising target for future therapy development is the pathway of cellular senescence that seems to play an important role in the pathogenesis of COPD and related comorbidities ${ }^{35,238}$. Other potential targets for new treatment developments include various cytokines or inflammatory molecules involved in the pathogenesis of COPD $\left(\right.$ ref. $^{239}$ ).

In terms of treatment, a completely new class of inhaled drugs (PDE3/4 inhibitors - ensifentrine, and PDE4 inhibitors) are expected to enter clinical practice soon $^{240,241}$. Bifunctional bronchodilator molecules with concurrent LABA and LAMA activity are already tested in clinical trials ${ }^{242}$. Similarly, biopharmaceuticals (particularly anti-IL-5) may be effective in specific subpopulations of patients ${ }^{81,243,244}$. For currently used treatments, real-life data from daily clinical practice are desired since only a minority of patients are eligible for participation in large RCTs (ref. ${ }^{245}$ ). This results in questionable effectiveness of approved treatments for the majority of patient populations. Of non-pharmacological treatment strategies, several new promising bronchoscopic treatment procedures have been developed in recent years, including endobronchial valves or coil placement or liquid nitrogen metered cryospray and targeted lung denervation procedures ${ }^{187,246,247}$. More emphasis should also be given to pulmonary rehabilitation programs and comorbidity management that are both evolving ${ }^{1,248}$.

Last but not least, more effort (and at all levels) should be given into preventive programs, measures against smoking and into improvements in occupational and environmental health.

Acknowledgements: The authors would like to thank $\mathrm{Mr}$ Jiri Kopecky for his help with the graphical layout of tables and graphs and to Pavol Pobeha MD, PhD. for his bright insight into the coincidence of obstructive sleep apnoea and COPD.

This work was supported by Ministry of Health of the Czech Republic (MH CZ-DRO FNBr 65269705). Supported by MH CZ - DRO (UHHK, 00179906), and by the program Charles University Progres Q40/08. Supported by MH CZ - DRO (FNO1, 00098892). Supported by the Czech Pneumological and Physiological Society (open access publication fee grant).

Author contributions: All authors contributed to the litera- 
ture search, conceptualization and writing of the manuscript; JZ, KB, VK: were the main authors of the position paper and are responsible for the integrity and completeness of the presented recommendations; KB: carried out the English language editing; All authors critically revised the manuscript for important intellectual content and approved the submitted version; All authors acknowledged that all questions related to the accuracy and integrity of all parts of the position paper were appropriately investigated and resolved.

Conflict of interest statement: Katerina Neumannova $(\mathrm{KN})$, Karel Hejduk (KH) and Michal Kopecky (MK) declare no conflict of interest with regard to this paper.

Kristian Brat (KB) received lecture fees from Boehringer Ingelheim, AstraZeneca and Chiesi, payments for advisory boards (Boehringer Ingelheim, Chiesi) and educational support from Boehringer Ingelheim, Angelini and CSL Behring. Vladimir Koblizek (VK) received COPD research funding from Boehringer Ingelheim and Novartis, and received consulting/lectures payments from Angelini, AstraZeneca, Berlin-Chemie, Boehringer Ingelheim, GSK, Novartis and Chiesi pertaining to the COPD field within the past 3 years. Jaromir Zatloukal (JZ) received consulting/lectures payments from Angelini, Berlin-Chemie, Boehringer Ingelheim, GSK, and Chiesi pertaining to the COPD field within the last 3 years. Marek Plutinsky (MP) reports personal fees from Boehringer Ingelheim, Berlin Chemie, and CSL Behring, outside the submitted work. Eva Volakova (EV) received lecture fees from Boehringer Ingelheim, AstraZeneca, GlaxoSmithKline and CSL Behring, payments for advisory boards (Boehringer Ingelheim, GlaxoSmithKline) and educational support from Boehringer Ingelheim, Chiesi and CSL Behring. Ondrej Kudela (OK) received lecture fees from Boehringer Ingelheim, AstraZeneca and Chiesi and fees for advisory board from Boehringer Ingelheim.

\section{REFERENCES}

1. Global Strategy for the Diagnosis, Management, and Prevention of Chronic Obstructive Pulmonary Disease. 2020 Report. [Cited: 2020 Sept 24]. Available from: https://goldcopd.org/wp-content/ uploads/2019/11/GOLD-2020-REPORT-ver1.1wms.pdf

2. Aisanov Z, Avdeev S, Arkhipov V, Belevskiy A, Chuchalin A, Leshchenko I, Ovcharenko S, Shmelev E, Miravitlles M. Russian guidelines for the management of COPD: algorithm of pharmacologic treatment. Int J Chron Obstruct Pulmon Dis 2018;13:183-87.

3. Miravitlles $M$, Soler-Cataluña JJ, Calle M, Molina J, Almagro $P_{1}$ Quintano JA, Trigueros JA, Cosío BG, Casanova C, Antonio Riesco J, Simonet P, Rigau D, Soriano JB, Ancochea J. Spanish Guidelines for Management of Chronic Obstructive Pulmonary Disease (GesEPOC) 2017. Pharmacological Treatment of Stable Phase. Arch Bronconeumol 2017;53(6):324-35.

4. Miravitlles M, Vogelmeier C, Roche N, Halpin D, Cardoso J, Chuchalin AG, Kankaanranta H, Sandström T, Śliwiński P, Zatloukal J, Blasi F. A review of national guidelines for management of COPD in Europe. Eur Respir J 2016;47(2):625-37.

5. Vukoja M, Kopitovic I, Lazic Z, Milenkovic B, Stankovic I, Zvezdin B, Dudvarski Ilic A, Cekerevac I, Vukcevic M, Zugic V, Hromis S. Diagnosis and management of chronic obstructive pulmonary disease in Serbia: an expert group position statement. Int J Chron Obstruct Pulmon Dis 2019;14:1993-2002.

6. Wedzicha JA, Calverley PMA, Albert RK, Anzueto A, Criner GJ, Hurst
JR, Miravitlles M, Papi A, Rabe KF, Rigau D, Sliwinski P, Tonia T, Vestbo J, Wilson KC, Krishnan JA. Prevention of COPD exacerbations: a European Respiratory Society/American Thoracic Society guideline. Eur Respir J 2017;50(3):1602265.

7. Zysman M, Chabot F, Devillier P, Housset B, Morelot-Panzini C, Roche N; Société de Pneumologie de Langue Française (SPLF). Pharmacological treatment optimization for stable chronic obstructive pulmonary disease. Proposals from the Société de Pneumologie de Langue Française. Rev Mal Respir 2016;33(10):911-36.

8. Kankaanranta H, Harju T, Kilpeläinen M, Mazur W, Lehto JT, Katajisto M, Peisa T, Meinander T, Lehtimäki L. Diagnosis and pharmacotherapy of stable chronic obstructive pulmonary disease: the finnish guidelines. Basic Clin Pharmacol Toxicol 2015;116(4):291-307.

9. Pleguezuelos E, Gimeno-Santos E, Hernández C, Mata MDC, Palacios L, Piñera P, Molina J, Chiner E, Miravitlles M. Recommendations on non-Pharmacological Treatment in Chronic Obstructive Pulmonary Disease From the Spanish COPD Guidelines (GesEPOC 2017). Arch Bronconeumol 2018;54(11):568-75.

10. Sliwiński P, Górecka D, Jassem E, Pierzchała W. Polish respiratory society guidelines for chronic obstructive pulmonary disease. Pneumonol Alergol Pol 2014;82(3):227-63.

11. Koblizek V, Chlumsky J, Zindr V, Neumannova K, Zatloukal J, Zak J, Sedlak V, Kocianova J, Zatloukal J, Hejduk K, Pracharova S; Czech Pneumological and Phthisiological Society. Chronic Obstructive Pulmonary Disease: official diagnosis and treatment guidelines of the Czech Pneumological and Phthisiological Society; a novel phenotypic approach to COPD with patient-oriented care. Biomed Pap Med Fac Univ Palacky Olomouc Czech Repub 2013;157(2):189-201.

12. Friedlander AL, Lynch D, Dyar LA, Bowler RP. Phenotypes of chronic obstructive pulmonary disease. COPD 2007;4(4):355-84.

13. Martin RJ, Bel EH, Pavord ID, Price D, Reddel HK. Defining severe obstructive lung disease in the biologic era: an endotype-based approach. Eur Respir J 2019;54:1900108.

14. Lowe KE, Regan EA, Anzueto A, Austin E, Austin JHM, Beaty TH, Benos PV, Benway CJ, Bhatt SP, Bleecker ER, Bodduluri S, Bon J, Boriek AM, Boueiz AR, Bowler RP, Budoff M, Casaburi R, Castaldi PJ, Charbonnier JP, Cho MH, Comellas A, Conrad D, Costa Davis C, Criner GJ, Curran-Everett D, Curtis JL, DeMeo DL, Diaz AA, Dransfield MT, Dy JG, Fawzy A, Fleming M, Flenaugh EL, Foreman MG, Fortis S, Gebrekristos H, Grant S, Grenier PA, Gu T, Gupta A, Han MK, Hanania NA, Hansel NN, Hayden LP, Hersh CP, Hobbs BD, Hoffman EA, Hogg JC, Hokanson JE, Hoth KF, Hsiao A, Humphries S, Jacobs K, Jacobson FL, Kazerooni EA, Kim V, Kim WJ, Kinney GL, Koegler H, Lutz SM, Lynch DA, Maclntye NR Jr, Make BJ, Marchetti N, Martinez FJ, Maselli DJ, Mathews AM, McCormack MC, McDonald MN, McEvoy CE, Moll M, Molye SS, Murray S, Nath $\mathrm{H}$, Newell JD Jr, Occhipinti M, Paoletti M, Parekh T, Pistolesi M, Pratte KA, Putcha N, Ragland M, Reinhardt JM, Rennard SI, Rosiello RA, Ross JC, Rossiter HB, Ruczinski I, San Jose Estepar R, Sciurba FC, Sieren JC, Singh $H$, Soler $X$, Steiner RM, Strand MJ, Stringer WW, TalSinger R, Thomashow B, Vegas Sánchez-Ferrero G, Walsh JW, Wan ES, Washko GR, Michael Wells J, Wendt CH, Westney G, Wilson A, Wise RA, Yen A, Young K, Yun J, Silverman EK, Crapo JD. COPDGene ${ }^{\circledR} 2019$ : Redefining the Diagnosis of Chronic Obstructive Pulmonary Disease. Chronic Obstr Pulm Dis 2019;6(5):384-99.

15. Young KA, Regan EA, Han MK, Lutz SM, Ragland M, Castaldi PJ, Washko GR, Cho MH, Strand M, Curran-Everett D, Beaty TH, Bowler RP, Wan ES, Lynch DA, Make BJ, Silverman EK, Crapo JD, Hokanson JE, Kinney GL; COPDGene ${ }^{\circledR}$ Investigators. Subtypes of COPD Have Unique Distributions and Differential Risk of Mortality. Chronic Obstr Pulm Dis 2019;6(5):400-13.

16. Vestbo J, Edwards LD, Scanlon PD, Yates JC, Agusti A, Bakke P Calverley PM, Celli B, Coxson HO, Crim C, Lomas DA, MacNee W, Miller BE, Silverman EK, Tal-Singer R, Wouters E, Rennard SI; ECLIPSE Investigators. Changes in forced expiratory volume in 1 second over time in COPD. N Engl J Med 2011;365(13):1184-92.

17. Barnes PJ. Inflammatory mechanisms in patients with chronic obstructive pulmonary disease. J Allergy Clin Immunol 2016;138(1):1627.

18. Singh D, Kolsum U, Brightling CE, Locantore N, Agusti A, Tal-Singer $\mathrm{R}$; ECLIPSE investigators. Eosinophilic inflammation in COPD: prevalence and clinical characteristics. Eur Respir J 2014;44(6):1697-700.

19. Tashkin DP, Wechsler ME. Role of eosinophils in airway inflammation of chronic obstructive pulmonary disease. Int J Chron Obstruct Pulmon Dis 2018;13:335-49. 
20. Polosukhin VV, Richmond BW, Du RH, Cates JM, Wu P, Nian H, Massion PP, Ware LB, Lee JW, Kononov AV, Lawson WE, Blackwell TS. Secretory IgA Deficiency in Individual Small Airways Is Associated with Persistent Inflammation and Remodeling. Am J Respir Crit Care Med 2017;195(8):1010-21.

21. Hogg JC, Timens W. The pathology of chronic obstructive pulmonary disease. Annu Rev Pathol 2009;4:435-59.

22. McDonough JE, Yuan R, Suzuki M, Seyednejad N, Elliott WM, Sanchez PG, Wright AC, Gefter WB, Litzky L, Coxson HO, Paré PD, Sin DD, Pierce RA, Woods JC, McWilliams AM, Mayo JR, Lam SC, Cooper JD, Hogg JC. Small-airway obstruction and emphysema in chronic obstructive pulmonary disease. N Engl J Med 2011;365(17):1567-75.

23. Elbehairy AF, Ciavaglia CE, Webb KA, Guenette JA, Jensen D, Mourad SM, Neder JA, O'Donnell DE; Canadian Respiratory Research Network. Pulmonary Gas Exchange Abnormalities in Mild Chronic Obstructive Pulmonary Disease. Implications for Dyspnea and Exercise Intolerance. Am J Respir Crit Care Med 2015;191(12):138494.

24. Miravitlles M, Calle M, Soler-Cataluña JJ. Clinical phenotypes of COPD: identification, definition and implications for guidelines. Arch Bronconeumol 2012:48(3):86-98.

25. Agusti A, Bel E, Thomas M, Vogelmeier C, Brusselle G, Holgate $S$, Humbert M, Jones P, Gibson PG, Vestbo J, Beasley R, Pavord ID. Treatable traits: toward precision medicine of chronic airway diseases. Eur Respir J 2016;47(2):410-19.

26. Franssen FM, Alter P, Bar N, Benedikter BJ, lurato S, Maier D, Maxheim M, Roessler FK, Spruit MA, Vogelmeier CF, Wouters EF, Schmeck B. Personalized medicine for patients with COPD: where are we? Int J Chron Obstruct Pulmon Dis 2019;14:1465-84.

27. King PT. Inflammation in chronic obstructive pulmonary disease and its role in cardiovascular disease and lung cancer. Clin Transl Med 2015;4(1):68.

28. Garcia-Rio F, Miravitlles $M$, Soriano JB, Muñoz L, Duran-Tauleria $E_{4}$ Sánchez G, Sobradillo V, Ancochea J; EPI-SCAN Steering Committee. Systemic inflammation in chronic obstructive pulmonary disease: a population-based study. Respir Res 2010;11:63.

29. Kim HC, Mofarrahi M, Hussain SN. Skeletal muscle dysfunction in patients with chronic obstructive pulmonary disease. Int J Chron Obstruct Pulmon Dis 2008;3(4):637-58.

30. Chen YW, Ramsook AH, Coxson HO, Bon J, Reid WD. Prevalence and Risk Factors for Osteoporosis in Individuals With COPD: A Systematic Review and Meta-analysis. Chest 2019;156(6):1092-1110.

31. Lu Y, Feng L, Feng L, Nyunt MS, Yap KB, Ng TP. Systemic inflammation, depression and obstructive pulmonary function: a populationbased study. Respir Res 2013;14:53.

32. Hersh CP, Make BJ, Lynch DA, Barr RG, Bowler RP, Calverley PM, Castaldi PJ, Cho MH, Coxson HO, DeMeo DL, Foreman MG, Han MK, Harshfield BJ, Hokanson JE, Lutz S, Ramsdell JW, Regan EA, Rennard SI, Schroeder JD, Sciurba FC, Steiner RM, Tal-Singer R, van Beek E Jr, Silverman EK, Crapo JD; COPDGene and ECLIPSE Investigators. Non-emphysematous chronic obstructive pulmonary disease is associated with diabetes mellitus. BMC Pulm Med 2014;14:164.

33. Agustí A, Edwards LD, Rennard SI, MacNee W, Tal-Singer R, Miller BE, Vestbo J, Lomas DA, Calverley PM, Wouters E, Crim C, Yates JC Silverman EK, Coxson HO, Bakke P, Mayer RJ, Celli B; Evaluation of COPD Longitudinally to Identify Predictive Surrogate Endpoints (ECLIPSE) Investigators. Persistent systemic inflammation is associated with poor clinical outcomes in COPD: a novel phenotype. PLoS One 2012;7(5):e37483.

34. de Torres JP, Marín JM, Casanova C, Cote C, Carrizo S, Cordoba-Lanus E, Baz-Dávila R, Zulueta JJ, Aguirre-Jaime A, Saetta M, Cosio MG, Celli BR. Lung cancer in patients with chronic obstructive pulmonary disease - incidence and predicting factors. Am J Respir Crit Care Med 2011;184(8):913-9.

35. Barnes PJ, Baker J, Donnelly LE. Cellular Senescence as a Mechanism and Target in Chronic Lung Diseases. Am J Respir Crit Care Med 2019;200(5):556-64.

36. Soriano JB, Lamprecht $B$, Ramírez AS, Martinez-Camblor $P$, Kaiser B, Alfageme I, Almagro P, Casanova C, Esteban C, Soler-Cataluña JJ, de-Torres JP, Miravitlles M, Celli BR, Marin JM, Puhan MA, Sobradillo $P$, Lange $P$, Sternberg AL, Garcia-Aymerich J, Turner AM, Han MK, Langhammer A, Leivseth L, Bakke P, Johannessen A, Roche N, Sin DD. Mortality prediction in chronic obstructive pulmonary disease comparing the GOLD 2007 and 2011 staging systems: a pooled analysis of individual patient data. Lancet Respir Med 2015;3(6):443-50.
37. Bui DS, Burgess JA, Lowe AJ, Perret JL, Lodge CJ, Bui M, Morrison S, Thompson BR, Thomas PS, Giles GG, Garcia-Aymerich J, Jarvis D, Abramson MJ, Walters EH, Matheson MC, Dharmage SC. Childhood Lung Function Predicts Adult Chronic Obstructive Pulmonary Disease and Asthma-Chronic Obstructive Pulmonary Disease Overlap Syndrome. Am J Respir Crit Care Med 2017;196(1):39-46.

38. Barker DJ, Godfrey KM, Fall C, Osmond C, Winter PD, Shaheen SO. Relation of birth weight and childhood respiratory infection to adult lung function and death from chronic obstructive airways disease. BMJ 1991;303(6804):671-5.

39. Broström EB, Akre O, Katz-Salamon M, Jaraj D, Kaijser M. Obstructive pulmonary disease in old age among individuals born preterm. Eur J Epidemiol 2013;28(1):79-85.

40. Hayden LP, Hobbs BD, Cohen RT, Wise RA, Checkley W, Crapo JD, Hersh CP; COPDGene Investigators. Childhood pneumonia increases risk for chronic obstructive pulmonary disease: the COPDGene study. Respir Res 2015;16:115.

41. Tagiyeva N, Devereux G, Fielding S, Turner S, Douglas G. Outcomes of childhood asthma and wheezy bronchitis. A 50-year cohort study. Am J Respir Crit Care Med 2016;193(1):23-30.

42. Allwood BW, Myer L, Bateman ED. A systematic review of the association between pulmonary tuberculosis and the development of chronic airflow obstruction in adults. Respiration 2013;86(1):76-85.

43. Byrne AL, Marais BJ, Mitnick CD, Lecca L, Marks GB. Tuberculosis and chronic respiratory disease: a systematic review. Int J Infect Dis 2015;32:138-46.

44. Bigna JJ, Kenne AM, Asangbeh SL, Sibetcheu AT. Prevalence of chronic obstructive pulmonary disease in the global population with HIV: a systematic review and meta-analysis. Lancet Glob Health 2018;6(2):e193-e202.

45. Yuan C, Chang D, Lu G, Den X. Genetic polymorphism and chronic obstructive pulmonary disease. Int J Chron Obstruct Pulmon Dis 2017;12:1385-93.

46. Greulich T, Nell C, Hohmann D, Grebe M, Janciauskiene S, Koczulla $A R$, Vogelmeier CF. The prevalence of diagnosed a1-antitrypsin deficiency and its comorbidities: results from a large population-based database. Eur Respir J 2017;49(1):1600154.

47. Miravitlles M, Dirksen A, Ferrarotti I, Koblizek V, Lange P, Mahadeva R, McElvaney NG, Parr D, Piitulainen E, Roche N, Stolk J, Thabut G, Turner A, Vogelmeier C, Stockley RA. European Respiratory Society statement: diagnosis and treatment of pulmonary disease in a(1)antitrypsin deficiency. Eur Respir J 2017;50(5):1700610.

48. Ding Z, Wang K, Li J, Tan Q, Tan W, Guo G. Association between glutathione S-transferase gene $\mathrm{M} 1$ and $\mathrm{T} 1$ polymorphisms and chronic obstructive pulmonary disease risk: A meta-analysis. Clin Genet 2019;95(1):53-62.

49. Houghton AM. Matrix metalloproteinases in destructive lung disease. Matrix Biol 2015;44-46:167-74.

50. Guo F, Kuang JL. Superoxide dismutase gene polymorphisms and functional activity in chronic obstructive pulmonary disease. Zhonghua Jie He He Hu Xi Za Zhi 2011;34(6):424-28.

51. Burgel PR, Laurendeau C, Raherison C, Fuhrman C, Roche N. An attempt at modeling COPD epidemiological trends in France. Respir Res 2018;19(1):130.

52. Adeloye D, Chua S, Lee C, Basquill C, Papana A, Theodoratou E, Nair H, Gasevic D, Sridhar D, Campbell H, Chan KY, Sheikh A, Rudan I; Global Health Epidemiology Reference Group (GHERG). Global and regional estimates of COPD prevalence: Systematic review and meta-analysis. J Glob Health 2015;5(2):020415.

53. Blanco I, Diego I, Bueno P, Fernández E, Casas-Maldonado F, Esquinas C, Soriano JB, Miravitlles M. Geographical distribution of COPD prevalence in Europe, estimated by an inverse distance weighting interpolation technique. Int J Chron Obstruct Pulmon Dis 2017;13:57-67.

54. Koblizek V, Jarkovsky J, Dusek L, Benesova K, Svoboda M, Brat K. The Czechia COPD mortality rate declining, but total deaths increasing. Eur Respir J 2020;56(suppl 64):434. In press.

55. GBD 2013 Mortality and Causes of Death Collaborators. Global, regional, and national age-sex specific all-cause and cause-specific mortality for 240 causes of death, 1990-2013: a systematic analysis for the Global Burden of Disease Study 2013. Lancet 2015;385:117-71.

56. López-Campos JL, Ruiz-Ramos M, Soriano JB. Mortality trends in chronic obstructive pulmonary disease in Europe, 1994-2010: a joinpoint regression analysis. Lancet Respir Med 2014;2(1):54-62.

57. Vondra V, Malý M. Výrazný vzestup úmrtnosti na chronickou 
obstrukční plicní nemoc v České republice v letech 2013-2017. Studia Pneumol Phthiseol 2019;79(2):43-50. (In Czech)

58. Celli BR, Cote CG, Marin JM, Casanova C, Montes de Oca M, Mendez RA, Pinto Plata V, Cabral HJ. The body-mass index, airflow obstruction, dyspnea, and exercise capacity index in chronic obstructive pulmonary disease. N Engl J Med 2004;350(10):1005-12.

59. Puhan MA, Garcia-Aymerich J, Frey M, ter Riet G, Antó JM, Agustí AG, Gómez FP, Rodríguez-Roisín R, Moons KG, Kessels AG, Held U. Expansion of the prognostic assessment of patients with chronic obstructive pulmonary disease: the updated BODE index and the ADO index. Lancet 2009;374(9691):704-11.

60. Brat K, Svoboda M, Hejduk K, Plutinsky M, Zatloukal J, Volakova E, Popelkova P, Novotna B, Engova D, Franssen FME, Vanfleteren LEGW Spruit MA, Koblizek V..Introducing a new prognostic instrument for long-term mortality prediction in COPD patients: the CADOT index. Biomed Pap Med Fac Univ Palacky Olomouc Czech Repub 2020; in press. doi: 10.5507/bp.2020.035

61. Cundrle I Jr, Johnson BD, Somers VK, Scott CG, Rea RF, Olson LJ. Effect of cardiac resynchronization therapy on pulmonary function in patients with heart failure. Am J Cardiol 2013;112(6):838-42.

62. Brat K, Plutinsky M, Hejduk K, Svoboda M, Popelkova P, Zatloukal J, Volakova E, Fecaninova M, Heribanova L, Koblizek V. Respiratory parameters predict poor outcome in COPD patients, category GOLD 2017 B. Int J Chron Obstruct Pulmon Dis 2018;13:1037-52.

63. Qaseem A, Wilt TJ, Weinberger SE, Hanania NA, Criner G, van der Molen T, Marciniuk DD, Denberg T, Schünemann $\mathrm{H}$, Wedzicha W, MacDonald R, Shekelle P. Diagnosis and management of stable chronic obstructive pulmonary disease: a clinical practice guideline update for the ACP, ACCP, ATS and ERS. Ann Intern Med 2011;155(3):179-91.

64. Pellegrino R, Viegi G, Brusasco V, Crapo RO, Burgos F, Casaburi R, Coates A, van der Grinten CP, Gustafsson P, Hankinson J, Jensen R, Johnson DC,MacIntyre N, McKay R, Miller MR, Navajas D, Pedersen $\mathrm{OF}$, Wanger J. Interpretative strategies for lung function tests. Eur Respir J 2005;26(5):948-68.

65. Graham BL, Steenbruggen I, Miller MR, Barjaktarevic IZ, Cooper BG, Hall GL, Hallstrand TS, Kaminsky DA, McCarthy K, McCormack MC, Oropez CE, Rosenfeld M, Stanojevic S, Swanney MP, Thompson BR. Standardization of Spirometry 2019 Update. An Official American Thoracic Society and European Respiratory Society Technical Statement. Am J Respir Crit Care Med 2019;200(8):e70-e88.

66. Chassagnon G, Brun AL, Bennani S, Chergui N, Freche G, Revel MP. Imagerie des dilatations des bronches [Bronchiectasis imaging]. Rev Pneumol Clin 2018;74(5):299-314.

67. Rosenow T. Quantification of CT bronchiectasis and its relationship to ventilation in cystic fibrosis. Thorax 2018;73(1):4.

68. Schmidt H, Sharma G. Sweat Testing. 2020 Jul 10. In: StatPearls [Internet]. Treasure Island (FL): StatPearls Publishing; 2020 Jan-. PMID: 31613508.

69. Corbelli R, Bringolf-Isler B, Amacher A, Sasse B, Spycher M, Hammer J. Nasal nitric oxide measurements to screen children for primary ciliary dyskinesia. Chest 2004;126(4):1054-59.

70. Walker WT, Jackson CL, Lackie PM, Hogg C, Lucas JS. Nitric oxide in primary ciliary dyskinesia. Eur Respir J 2012;40(4):1024-32.

71. Agusti A. The path to personalised medicine in COPD. Thorax 2014;69(9):857-64.

72. Siafakas N, Corlateanu A, Fouka E. Phenotyping Before Starting Treatment in COPD? COPD 2017;14(3):367-74.

73. Han MK, Agusti A, Calverley PM, Celli BR, Criner G, Curtis JL, Fabbri LM, Goldin JG, Jones PW, Macnee W, Make BJ, Rabe KF, Rennard SI, Sciurba FC,Silverman EK, Vestbo J, Washko GR, Wouters EF, Martinez FJ. Chronic obstructive pulmonary disease phenotype. The future of COPD. Am J Respir Crit Care Med 2010;182(5):598-604.

74. Burgel PR, Paillasseur JL, Caillaud D, Tillie-Leblond I, Chanez $\mathrm{P}_{t}$ Escamilla R, Court-Fortune I, Perez T, Carré P, Roche N. Clinical COPD phenotypes: a novel approach using principal component and cluster analyses. Eur Respir J 2010;36(3):531-39.

75. Gonem S, Raj V, Wardlaw J, Pavord ID, Green R, Siddiqui S. Phenotyping airways disease: an A to E approach. Clinical Et Experimental Allergy 2012;42(12):1664-83.

76. Anzueto A, Miravitlles M. Pathophysiology of dyspnea in COPD. Postgrad Med 2017;129(3):366-74.

77. Wu ZY, Han YX, Niu ME, Chen Y, Zhang XQ, Qian HY. Handgrip strength is associated with dyspnoea and functional excercise capacity in male patients with stable COPD. Int J Tuberc Lung Dis 2019;23(4):428-32.

78. Laviolette L, Laveneziana P; ERS Research Seminar Faculty. Dypnoea: a multidimensional and multidisciplinary approach. Eur Respir J 2014;43(6):1750-62.

79. Kouijzer M, Brusse-Keizer M, Bode C. COPD-related fatigue: Impact on daily life and treatment opportunities from the patient's perspective. Respir Med 2018;141:47-51.

80. Goërtz YMJ, Spruit MA, Van 't Hul AJ, Peters JB, Van Herck M, Nakken N, Djamin RS, Burtin C, Thong MSY, Coors A, Meertens-Kerris $Y$, Wouters EFM, Prins JB, Franssen FME, Muris JWM, Vanfleteren LEGW, Sprangers MAG, Janssen DJA, Vercoulen JH. Fatigue is highly prevalent in patients with COPD and correlates poorly with the degree of airflow limitation. Ther Adv Respir Dis 2019;13:1753466619878128.

81. Pavord ID, Chanez P, Criner GJ, Kerstjens HAM, Korn S, Lugogo $N$, Martinot JB, Sagara H, Albers FC, Bradford ES, Harris SS, Mayer B, Rubin DB, Yancey SW, Sciurba FC. Mepolizumab for Eosinophilic Chronic Obstructive Pulmonary Disease. N Engl J Med 2017;377(17):1613-29.

82. Mirza S, Benzo R. Chronic Obstructive Pulmonary Disease Phenotypes: Implications for Care. Mayo Clin Proc 2017;92(7):110412.

83. Le Rouzic O, Roche N, Cortot AB, Tillie-Leblond I, Masure F, Perez T, Boucot I, Hamouti L, Ostinelli J, Pribil C, Poutchnine C, Schück S, Pouriel M, Housset B. Definig the "Frequent Exacerbator" Phenotype in COPD: A Hypothesis-Free Approach. Chest 2018;153(5):1106-15.

84. Hurst JR. Exacerbation phenotyping in chronic obstructive pulmonary disease. Am J Respir Crit Care Med 2011;184(6):625-26.

85. Aaron SD, Donaldson GC, Whitmore GA, Hurst JR, Ramsay T, Wedzicha JA.Time course and pattern of COPD exacerbation onset. Thorax 2012;67(3):238-43.

86. George C, Zermansky W, Hurst JR. Frequent exacerbations in chronic obstructive pulmonary disease. BMJ 2011;342:d1434.

87. Chalmers JD, Aliberti S, Filonenko A, Shteinberg M, Goeminne PC, Hill AT, Fardon TC, Obradovic D, Gerlinger C, Sotgiu G, Operschall E, Rutherford RM, Dimakou K, Polverino E, De Soyza A, McDonnell MJ. Characterization of the "Frequent Exacerbator Phenotype" in Bronchiectasis. Am J Respir Crit Care Med 2018;197(11):1410-20.

88. Sun P, Ye R, Wang C, Bai S, Zhao L. Identification of proteomic signatures associated with COPD frequent exacerbators. Life Sci 2019;230:1-9.

89. Koblizek V, Tomsova M, Cermakova E, Papousek P, Pracharova S, Mandalia RA, Ceral J, Novosad J, Fila L, Sedlak V, Ruta J, Bartos V, Salajka F, Hrnciarik M. Impairment of nasal mucociliary clearance in former smokers with stable chronic obstructive pulmonary disease relates to the presence of a chronic bronchitis phenotype. Rhinology 2011;49(4):397-406.

90. Koblizek V, Milenkovic B, Barczyk A, Tkacova R, Somfay A, Zykov K, Tudoric N, Kostov K, Zbozinkova Z, Svancara J, Sorli J, Krams A, Miravitlles M, Valipour A. Phenotypes of COPD patients with a smoking history in Central and Eastern Europe: the POPE Study. Eur Respir J 2017;49(5):1601446.

91. Kim V, Han MK, Vance GB, Make BJ, Newell JD, Hokanson JE, Hersh $C P$, Stinson D, Silverman EK, Criner GJ; COPDGene Investigators. The chronic bronchitic phenotype of COPD: an analysis of the COPDGene Study. Chest 2011;140(3):626-33.

92. Antonelli Incalzi R, Canonica GW, Scichilone N, Rizzoli S, Simoni L, Blasi F; STORICO study group. The COPD multi-dimensional phenotype: A new classification from the STORICO Italian observational study. PLoS One 2019;14(9):e0221889.

93. Cheng Y, Tu X, Pan L, Lu S, Xing M, Li L, Chen X. Clinical characteristics of chronic bronchitic, emphysematous and ACOS phenotypes in COPD patients with frequent exacerbations. Int J Chron Obstruct Pulmon Dis 2017;12:2069-74

94. Suzuki M, Sze MA, Campbell JD, Brothers JF 2nd, Lenburg ME, McDonough JE, Elliott WM, Cooper JD, Spira A, Hogg JC. The cellular and molecular determinants of emphysematous destruction in COPD. Sci Rep 2017;7(1):9562.

95. Oh YM, Sheen SS, Park JH, Jin UR, Yoo JW, Seo JB, Yoo KH, Lee JH, Kim $\mathrm{TH}$, Lim SY, Yoon HI, Lee JS, Lee SD. Emphysematous phenotype in an independent predictor for frequent exacerbation of COPD. Int J Tuberc Lung Dis 2014;18(12):1407-14.

96. Lynch DA, Austin JH, Hogg JC, Grenier PA, Kauczor HU, Bankier AA, 
Barr RG, Colby TV, Galvin JR, Gevenois PA, Coxson HO, Hoffman EA, Newell JD Jr, Pistolesi M, Silverman EK, Crapo JD. CT-Definable Subtypes of Chronic Obstructive Pulmonaty Disease: A Statement of the Fleischner Society. Radiology 2015;277(1):192-205.

97. Janssen R, Piscaer I, Franssen FME, Wouters EFM. Emphysema: looking beyond alpha-1 antitrypsin deficiency. Expert Rev Respir Med 2019;13(4):381-97.

98. Papaioannou Al, Kostikas K, Papaporfyriou A, Angelakis L, Papathanasiou E, Hillas G, Mazioti A, Bakakos P, Koulouris N, Papiris $\mathrm{S}$, Loukides S. Emphysematous Phenotype is Characterized by Low Blood Eosinophils: A Cross-Sectional Study. COPD 2017;14(6):635 40.

99. Sorino C, Scichilone N, D'Amato M, Patella V, DI Marco F. AsthmaCOPD overlap syndrome associated with a sputum eosinophi count $\geq 3 \%$ in a cohort of unselected patients with asthma. Minerva Med 2017;108(3 Suppl 1):1-5.

100. Tho NV, Park HY, Nakano Y. Asthma-COPD overlap syndrome (ACOS): A diagnostic challenge. Respirology 2016;21(3):410-18.

101. Leung JM, Sin DD. Asthma-COPD overlap syndrome: pathogenesis, clinical features, and therapeutic targets. BMJ 2017;358:j3772.

102. Takiguchi $\mathrm{H}$, Asano K. Asthma-COPD overlap syndrome (ACOS). Nihon Rinsho 2016;74(5):778-82.

103. Plaza V, Álvarez F, Calle M, Casanova C, Cosío BG, López-Viña A Pérez de Llano L, Quirce S, Román-Rodríguez M, Soler-Cataluña J Miravitlles M. Consensus on the Asthma-COPD Overlap Syndrome (ACOS) Between the Spanish COPD Guidelines (GesEPOC) and the Spanish Guidelines on the Management of Asthma (GEMA). Arch Bronconeumol 2017;53(8):443-49.

104. Cosío BG, Dacal D, Pérez de Llano L. Asthma-COPD overlap: identification and optimal treatment. Ther Adv Respir Dis 2018;12:1753466618805662.

105. Toledo-Pons N, van Boven JFM, Román-Rodríguez $M$, Pérez $N$, Valera Felices JL, Soriano JB, Cosío BG. ACO: Time to move from the description of different phenotypes to the treatable traits. PLoS One 2019;14(1):e0210915.

106. Schleich FN, Seidel L, Sele J, Manise M, Quaedvlieg V, Michils A, Louis R. Exhaled nitric oxide tresholds associated with a sputum eosinophil count $\geq 3 \%$ in a cohort of unselected patients with asthma. Thorax 2010;65(12):1039-44.

107. Martinez-Garcia MA, Miravitlles M. Bronchiectasis in COPD patients: more than a comorbidity? Int J Chron Obstruct Pulmon Dis 2017;12:1401-11.

108. Polverino E, Dimakou K, Hurst J, Martinez-Garcia MA, Miravitlles M, Paggiaro P, Shteinberg M, Aliberti S, Chalmers JD. The overlap between bronchiectasis and chronic airway diseases: state of the art and future directions. Eur Respir J 2018;52(3):1800328.

109. Padilla-Galo A, Olveira Fuster C. Bronchiectasis in COPD and Asthma. More Than Just a Coincidence. Arch Bronconeumo 2019;55(4):181-82.

110. Poh TY, Mac Aogáin M, Chan AK, Yii AC, Yong VF, Tiew PY, Koh MS Chotirmall SH. Understanding COPD-overlap syndromes. Expert Rev Respir Med 2017;11(4):285-98.

111. Sánchez-Muñoz G, Lopez-de-Andrés A, Hernández-Barrera $V$ Jiménez-García R, Pedraza-Serrano F, Puente-Maestu L, de MiguelDíez J. Bronchiectasis in patients hospitalized with acute exacerbation of COPD in Spain: Influence of mortality, hospital stay, and hospital costs (2006-2014) according to gender. PLoS One 2019;14(1):e0211222.

112. Yu Q, Peng H, Li B, Qian H, Zhang H. Characteristics and related factors of bronchiectasis in chronic obstructive pulmonary disease. Medicine (Baltimore). 2019;98(47):e17893.

113. Kwan HY, Maddocks M, Nolan CM, Jones SE, Patel S, Barker RE, Kon SSC, Polkey MI, Cullinan P, Man WD. The prognostic signifikance of wieght loss in chronic obstructive pulmonary disease - related cachexia: a prospective cohort study. J Cachexia Sarcopenia Muscle 2019;10(6):1330-38

114. Mokari-Yamchi A, Jabbari M, Sharifi A, Barati M, Kheirouri S. Low FE1 Is Associated With Increased Risk Of Cachexia In COPD Patients. Int J Chron Obstruct Pulmon Dis 2019;14:2433-40.

115. Itoh M, Tsuji T, Nemoto K, Nakamura H, Aoshiba K. Undernutrition in patients with COPD and its treatment. Nutrients 2013;5(4):1316-35.

116. Sanchez FF, Faganello MM, Tanni SE, Lucheta PA, Pelegrino NG, Hasegawa SH, Ribeiro SM, Godoy I. Anthropometric midarm measurements can detect systemic fat-free mass depletion in pa-tients with chronic obstructive pulmonary disease. Braz J Med Biol Res 2011;44(5):453-59.

117. Lainscak M, von Haehling S, Doehner W, Sarc I, Jeric T, Ziherl K, Kosnik M, Anker SD, Suskovic S. Body mass index and prognosis in patients hospitalized with acute exacerbation of chronic obstructive pulmo- nary disease. J Cachexia Sarcopenia Muscle 2011;2(2):81-86.

118. Wagner PD. Possible mechanisms underlying the development of cachexia in COPD. Eur Respir J 2008;31(3):492-501.

119. McDonald MN, Wouters EFM, Rutten E, Casaburi R, Rennard SI, Lomas DA, Bamman M, Celli B, Agusti A, Tal-Singer R, Hersh $C P$, Dransfield $M$, Silverman EK. It's more than low BMI: prevalence of cachexia and associated mortality in COPD. Respir Res 2019;20(1):100.

120. Brat K, Plutinsky M, Koblizek V, Zatloukal J, Popelkova P, Dvorak T, Safranek P, Rakita D, Vanik P, Liptakova Z, Heribanova L, Musilova P, Sipkova M, Kocova E, Novotna B, Kudela O, Kopecky M, Neumannova K, Svoboda M, Jarkovsky J, Zbozinkova Z, Svancara J, Lnenicka J, Rihak V. Cluster phenotyping as an approach to identify COPD patients at risk of poor prognosis. Eur Respir J 2018;52(suppl 62):PA3853.

121. Ajmera M, Sambamoorthi U, Metzger A, Dwibedi N, Rust G, Tworek C. Multimorbidity and COPD Medication Receipt Among Medicaid Beneficiaries With Newly Diagnosed COPD. Respir Care 2015;60(11):1592-602.

122. Jantunen J, Haahtela T, Salimäki J, Linna $M$, Mäkelä $M$, Pelkonen A, Kauppi P. Multimorbidity in Asthma, Allergic Conditions and COPD Increase Disease Severity, Drug Use and Costs: The Finnish Pharmacy Survey. Int Arch Allergy Immunol 2019;179(4):273-80.

123. Spyratos D, Haidich AB, Chloros D, Michalopoulou D, Sichletidis L. COPD screening program: What is appropriate target group population? Respiration 2017;94(1):74.

124. Spyratos D, Haidich AB, Chloros D, Michalopoulou D, Sichletidis L. Comparison of three screening questionnaires for chronic obstructive pulmonary disease in the primary care. Respiration 2017;93:8389.

125. Ulrik CS, Løkke A, Dahl R, Dollerup J, Hansen G, Cording PH, Andersen KK, TOP study group. Early detection of COPD in general practice. Int J Chron Obstruct Pulmon Dis 2011;6:123-27.

126. Jiménez-Ruiz CA, Andreas $S$, Lewis KE, Tonnesen $P$, van Schayck $C P$, Hajek P, Tonstad S, Dautzenberg B, Fletcher M, Masefield S, Powell $P$, Hering T, Nardini S, Tonia T, Gratziou C. Statement on smoking cessation in COPD and other pulmonary diseases and in smokers with comorbidities who find it difficult to quit. Eur Respir $J$ 2015;46(1):61-79.

127. Hoogendoorn M, Feenstra TL, Hoogenveen RT, Rutten-van Mölken MP. Long-term effectiveness and cost-effectiveness of smoking cessation interventions in patients with COPD. Thorax 2010;65(8):71118.

128. Johannessen A, Bakke PS, Hardie JA, Eagan TM. Association of exposure to environmental tobacco smoke in childhood with chronic obstructive pulmonary disease and respiratory symptoms in adults. Respirology 2012;17(3):499-505.

129. Beeh KM. The Role of Bronchodilators in Preventing Exacerbations of Chronic Obstructive Pulmonary Disease. Tuberc Respir Dis (Seoul) 2016;79(4):241-47.

130. Wedzicha JA, Decramer M, Seemungal TA. The role of bronchodilator treatment in the prevention of exacerbations of COPD. Eur Respir J 2012;40(6):1545-54.

131. Tashkin DP, Celli B, Senn S, Burkhart D, Kesten S, Menjoge S, Decramer M; UPLIFT Study Investigators. A 4-year trial of tiotropium in chronic obstructive pulmonary disease. N Engl J Med 2008;359(15):1543-54

132. Calverley PM, Anderson JA, Celli B, Ferguson GT, Jenkins C, Jones PW, Yates JC, Vestbo J; TORCH investigators. Salmeterol and fluticasone propionate and survival in chronic obstructive pulmonary disease. N Engl J Med 2007;356(8):775-89.

133. Dusser D, Bravo ML, lacono $P$. The effect of tiotropium on exacerbations and airflow in patients with COPD. Eur Respir J 2006;27(3):54755.

134. Anzueto A, Miravitlles M. The Role of Fixed-Dose Dual Bronchodilator Therapy in Treating COPD. Am J Med 2018;131(6):608-22.

135. Singh D, D'Urzo AD, Donohue JF, Kerwin EM, Molins E, Chuecos F, Ribera A, Jarreta D. An Evaluation Of Single And Dual Long-Acting 
Bronchodilator Therapy As Effective Interventions In Maintenance Therapy-Naïve Patients With COPD. Int J Chron Obstruct Pulmon Dis 2019;14:2835-48.

136. Decramer ML, Chapman KR, Dahl R, Frith P, Devouassoux G, Fritscher C, Cameron R, Shoaib M, Lawrence D, Young D, McBryan D; INVIGORATE investigators. Once-daily indacaterol versus tiotropium for patients with severe chronic obstructive pulmonary disease (INVIGORATE): a randomised, blinded, parallel-group study. Lancet Respir Med 2013;1(7):524-33.

137. Vogelmeier C, Hederer B, Glaab T, Schmidt H, Rutten-van Mölken MP, Beeh KM, Rabe KF, Fabbri LM; POET-COPD Investigators. Tiotropium versus salmeterol for the prevention of exacerbations of COPD. N Engl J Med 2011;364(12):1093-1103.

138. Casaburi R, Kukafka D, Cooper CB, Witek TJ Jr, Kesten S Improvement in exercise tolerance with the combination of tiotropium and pulmonary rehabilitation in patients with COPD. Chest 2005;127(3):809-17.

139. Bateman ED, Ferguson GT, Barnes N, Gallagher N, Green Y, Henley M, Banerji D. Dual bronchodilation with QVA149 versus single bronchodilator therapy: the SHINE study. Eur Respir J 2013;42(6):1484 94.

140. Zhong N, Wang C, Zhou X, Zhang N, Humphries M, Wang L, Thach C, Patalano F, Banerji D; LANTERN Investigators. LANTERN: a randomized study of QVA149 versus salmeterol/fluticasone combination in patients with COPD. Int J Chron Obstruct Pulmon Dis 2015;10:101526.

141. Buhl R, Maltais F, Abrahams R, Bjermer L, Derom E, Ferguson G, Fležar M, Hébert J, McGarvey L, Pizzichini E, Reid J, Veale A, Grönke L, Hamilton A, Korducki L, Tetzlaff K, Waitere-Wijker S, Watz H, Bateman E. Tiotropium and olodaterol fixed-dose combination versus mono-components in COPD (GOLD 2-4). Eur Respir J 2015;45(4):969-79.

142. Bolton CE, Bevan-Smith EF, Blakey JD, Crowe P, Elkin SL, Garrod R, Greening NJ, Heslop K, Hull JH, Man WD, Morgan MD, Proud D, Roberts CM, Sewell L, Singh SJ, Walker PP, Walmsley S; British Thoracic Society Pulmonary Rehabilitation Guideline Development Group; British Thoracic Society Standards of Care Committee. British Thoracic Society guideline on pulmonary rehabilitation in adults. Thorax 2013;68 Suppl 2:ii1-30.

143. Spruit MA, Singh SJ, Garvey C, ZuWallack R, Nici L, Rochester C, Hill K, Holland AE, Lareau SC, Man WD, Pitta F, Sewell L, Raskin J, Bourbeau J, Crouch R, Franssen FM, Casaburi R, Vercoulen JH, Vogiatzis I, Gosselink R, Clini EM, Effing TW, Maltais F, van der Palen J, Troosters T, Janssen DJ, Collins E, Garcia-Aymerich J, Brooks D Fahy BF, Puhan MA, Hoogendoorn M, Garrod R, Schols AM, Carlin B, Benzo R, Meek P, Morgan M, Rutten-van Mölken MP, Ries AL, Make B, Goldstein RS, Dowson CA, Brozek JL, Donner CF, Wouters EF; ATS/ ERS Task Force on Pulmonary Rehabilitation. An official American Thoracic Society/European Respiratory Society statement: key concepts and advances in pulmonary rehabilitation. Am J Respir Crit Care Med 2013;188(8):e13-64.

144. Garvey C, Bayles MP, Hamm LF, Hill K, Holland A, Limberg TM, Spruit MA. Pulmonary Rehabilitation Exercise Prescription in Chronic Obstructive Pulmonary Disease: Review of Selected Guidelines: AN OFFICIAL STATEMENT FROM THE AMERICAN ASSOCIATION OF CARDIOVASCULAR AND PULMONARY REHABILITATION. J Cardiopulm Rehabil Prev 2016;36(2):75-83.

145. National Institute for Health and Care Excellence. Chronic obstruc tive pulmonary disease in over $16 \mathrm{~s}$ : diagnosis and management (NICE guideline) [NG 115]. Last updated July 2019. [Cited 2020, Aug 15]. Available from: https://www.nice.org.uk/guidance/NG115

146. Beauchamp MK, Sibley KM, Lakhani B, Romano J, Mathur S, Goldstein RS, Brooks D. Impairments in systems underlying control of balance in COPD. Chest 2012;141(6):1496-1503.

147. Jackson RA, Vittinghoff E, Kanaya AM, Miles TP, Resnick HE, Kritchevsky SB, Brown JS. Urinary incontinence in elderly women findings from the Health, Aging, and Body Composition Study. Obstetrics \& Gynecology 2004;104(2):301-07.

148. Lee AL, Harrison SL, Goldstein RS, Brooks D. Pain and its clinical associations in individuals with COPD: a systematic review. Chest 2015;147(5):1246-58

149. Smith MD, Chang AT, Seale HE, Walsh JR, Hodges PW. Balance is impaired in people with chronic obstructive pulmonary disease. Gait \& posture 2010;31(4):456-60.
150. Vytrisalova $M$, Hendrychova T, Touskova T, Zimcikova E, Vlcek J, Nevoranek L, Svoboda M, Hejduk K, Brat K, Plutinsky M, Novotna B, Musilova P, Cernohorsky M, Koblizek V. Breathing Out Completely Before Inhalation: The Most Problematic Step in Application Technique in Patients With Non-Mild Chronic Obstructive Pulmonary Disease. Front Pharmacol 2019;10:241.

151. Kašáková $E, K a s ̌ a ́ k ~ V$. Inhalační systémy na českém trhu pro léčbu pacientů s chronickou obstrukcí průdušek. Prakt. lékáren 2015;11(1):16-18. (In Czech)

152. Koblizek V, Kopecky M, Nevoranek L, Hornychova T, Vlcek J. Four years of targeted education are fundamentally changing the inhalation technique. Eur Respir J 2020;56(suppl 64):642. In press.

153. Froes F, Roche N, Blasi F. Pneumococcal vaccination and chronic respiratory diseases. Int J Chron Obstruct Pulmon Dis 2017;12:345768.

154. Collins PF, Elia M, Stratton RJ. Nutritional support and functional capacity in chronic obstructive pulmonary disease: a systematic review and meta-analysis. Respirology 2013;18(4):616-29.

155. Schols AM, Ferreira IM, Franssen FM, Gosker HR, Janssens W, Muscaritoli M, Pison C, Rutten-van Mölken M, Slinde F, Steiner MC, Tkacova R, Singh SJ. Nutritional assessment and therapy in COPD: a European Respiratory Society statement. Eur Respir J 2014;44(6):1504-20.

156. Lee RC, Wang Z, Heo M, Ross R, Janssen I, Heymsfield SB. Total-body skeletal muscle mass: development and cross-validation of anthropometric prediction models. Am J Clin Nutr 2000;72(3):796-803.

157. Slater GJ, Duthie GM, Pyne DB, Hopkins WG. Validation of a skinfold based index for tracking proportional changes in lean mass. $\mathrm{Br} J$ Sports Med 2006;40(3):208-13.

158. Voláková E, Zatloukal J, Svoboda M, Plutinsky M, Brat K, Novotna B, Popelkova P, Musilova P, Lnenicka J, Heribanova L, Liptakova Z, Dvorak T, Voglova P, Safranek P, Simek R, Nevoranek L, Kopecky M, Kocova E, Neumannova K, Skrobackova M, Koblizek V. Nutrition status and mortality rate during 5 -years follow-up in patients with COPD. Eur Respir J 2019;54(suppl 63):PA4307.

159. Pison CM, Cano NJ, Chérion C, Caron F, Court-Fortune I, Antonin MT, Gonzalez-Bermejo J, Meziane L, Molano LC, Janssens JP, Costes F, Wuyam B, Similowski T, Melloni B, Hayot M, Augustin J, Tardif C, Lejeune $\mathrm{H}$, Roth $\mathrm{H}$, Pichard C; IRAD Investigators. Multimodal nutritional rehabilitation improves clinical outcomes of malnourished patients with chronic respiratory failure: a randomised controlled trial. Thorax 2011;66(11):953-60.

160. Pinnock $H$, Steed $L$, Jordan R. Supported self-management for COPD: making progress, but there are still challenges. Eur Respir $J$ 2016;48(1):6-9.

161. Jonkman $\mathrm{NH}$, Westland $\mathrm{H}$, Trappenburg JC, Groenwold RH, Bischoff EW, Bourbeau J, Bucknall CE, Coultas D, Effing TW, Epton M, Gallefoss F, Garcia-Aymerich J, Lloyd SM, Monninkhof EM, Nguyen $\mathrm{HQ}$, van der Palen J, Rice KL, Sedeno M, Taylor SJ, Troosters T, Zwar NA, Hoes AW, Schuurmans MJ. Characteristics of effective self-management interventions in patients with COPD: individual patient data meta-analysis. Eur Respir J 2016;48(1):55-68.

162. Pumar MI, Gray CR, Walsh JR, Yang IA, Rolls TA, Ward DL. Anxiety and depression-Important psychological comorbidities of COPD. J Thorac Dis 2014;6(11):1615-31.

163. Yang IA, Clarke MS, Sim EH, Fong KM. Inhaled corticosteroids for stable chronic obstructive pulmonary disease. Cochrane Database Syst Rev 2012;(7):CD002991.

164. Bafadhel M, Peterson S, De Blas MA, Calverley PM, Rennard SI, Richter K, Fagerås M. Predictors of exacerbation risk and response to budesonide in patients with chronic obstructive pulmonary disease: a post-hoc analysis of three randomised trials. Lancet Respir Med 2018;6(2):117-126.

165. Pascoe S, Locantore N, Dransfield MT, Barnes NC, Pavord ID. Blood eosinophil counts, exacerbations, and response to the addition of inhaled fluticasone furoate to vilanterol in patients with chronic obstructive pulmonary disease: a secondary analysis of data from two parallel randomised controlled trials. Lancet Respir Med 2015;3(6):435-42.

166. Rossi A, Guerriero M, Corrado A; OPTIMO/AIPO Study Group. Withdrawal of inhaled corticosteroids can be safe in COPD patients at low risk of exacerbation: a real-life study on the appropriateness of treatment in moderate COPD patients (OPTIMO). Respir Res 2014;15(1):77. 
167. Magnussen $H$, Disse $B$, Rodriguez-Roisin $R$, Kirsten $A$, Watz $H_{\text {, }}$ Tetzlaff K, Towse L, Finnigan H, Dahl R, Decramer M, Chanez $\mathrm{P}$ Wouters EF, Calverley PM; WISDOM Investigators. Withdrawal of inhaled glucocorticoids and exacerbations of COPD. N Engl J Med 2014;371(14):1285-94.

168. Chapman KR, Hurst JR, Frent SM, Larbig M, Fogel R, Guerin T, Banerji D, Patalano F, Goyal P, Pfister P, Kostikas K, Wedzicha JA. Long-Term Triple Therapy De-escalation to Indacaterol/Glycopyrronium in Patients with Chronic Obstructive Pulmonary Disease (SUNSET): A Randomized, Double-Blind, Triple-Dummy Clinical Trial. Am J Respir Crit Care Med 2018;198(3):329-39.

169. Chalmers JD, Laska IF, Franssen FME, Janssens W, Pavord I, Rigau D, McDonnell MJ, Roche N, Sin DD, Stolz D, Suissa S Wedzicha J, Miravitlles M. Withdrawal of inhaled corticosteroids in COPD: a European Respiratory Society guideline. Eur Respir J 2020;55(6):2000351.

170. Kawamatawong T. Roles of roflumilast, a selective phosphodiesterase 4 inhibitor, in airway diseases. J Thorac Dis 2017;9(4):1144-54.

171. Bateman ED, Rabe KF, Calverley PM, Goehring UM, Brose M Bredenbröker D, Fabbri LM. Roflumilast with long-acting $\beta 2$ agonists for COPD: influence of exacerbation history. Eur Respir 2011;38(3):553-60.

172. Fabbri LM, Calverley PM, Izquierdo-Alonso JL, Bundschuh DS, Brose M, Martinez FJ, Rabe KF; M2-127 and M2-128 study groups. Roflumilast in moderate-to-severe chronic obstructive pulmonary disease treated with longacting bronchodilators: two randomised clinical trials. Lancet 2009;374(9691):695-703.

173. Martinez FJ, Calverley PM, Goehring UM, Brose M, Fabbri LM, Rabe KF. Effect of roflumilast on exacerbations in patients with severe chronic obstructive pulmonary disease uncontrolled by combination therapy (REACT): a multicentre randomised controlled trial. Lancet 2015;385:857-66.

174. Wang H, Peng MS, Chen Y, Geng J, Robinson H, Houslay MD, Cai J, $\mathrm{Ke} \mathrm{H}$. Structures of the four subfamilies of phosphodiesterase-4 provide insight into the selectivity of their inhibitors. Biochem J 2007;408(2):193-201.

175. Dal Negro RW, Wedzicha JA, Iversen M, Fontana G, Page C, Cicero AF, Pozzi E, Calverley PMA; RESTORE group; RESTORE study. Effect of erdosteine on the rate and duration of COPD exacerbations: the RESTORE study. Eur Respir J 2017;50(4):1700711.

176. Calverley PM, Page C, Dal Negro RW, Fontana G, Cazzola M, Cicero AF, Pozzi E, Wedzicha JA. Effect of Erdosteine on COPD Exacerbations in COPD Patients with Moderate Airflow Limitation. Int J Chron Obstruct Pulmon Dis 2019;14:2733-44.

177. Seemungal TA, Wilkinson TM, Hurst JR, Perera WR, Sapsford RJ, Wedzicha JA. Long-term erythromycin therapy is associated with decreased chronic obstructive pulmonary disease exacerbations. Am J Respir Crit Care Med 2008;178(11):1139-47.

178. Yamaya M, Azuma A, Takizawa H, Kadota J, Tamaoki J, Kudoh S. Macrolide effects on the prevention of COPD exacerbations. Eur Respir J 2012;40(2):485-94.

179. Cazzola M, Floriani I, Page CP. The therapeutic efficacy of erdosteine in the treatment of chronic obstructive bronchitis: a meta-analysis of individual patient data. Pulm Pharmacol Ther 2010;23(2):135-44.

180. Kim V, Criner GJ. Chronic bronchitis and chronic obstructive pulmonary disease. Am J Respir Crit Care Med 2013;187(3):228-37.

181. Zheng JP, Wen FQ, Bai CX, Wan HY, Kang J, Chen P, Yao WZ, Ma LJ, Li X, Raiteri L, Sardina M, Gao Y, Wang BS, Zhong NS; PANTHEON study group. Twice daily $\mathrm{N}$-acetylcysteine $600 \mathrm{mg}$ for exacerbations of chronic obstructive pulmonary disease (PANTHEON): a randomised, double-blind placebo-controlled trial. Lancet Respir Med 2014;2(3):187-94.

182. Sun Y, Zhou J. New insights into early intervention of chronic obstructive pulmonary disease with mild airflow limitation. Int J Chron Obstruct Pulmon Dis 2019;14:1119-25.

183. Vaz Fragoso CA, Miller MA. Review of the clinical efficacy of theophylline in the treatment of chronic obstructive pulmonary disease. Am Rev Respir Dis 1993;147:S40.

184. ZuWallack RL, Mahler DA, Reilly D, Church N, Emmett A, Rickard K, Knobil K. Salmeterol plus theophylline combination therapy in the treatment of COPD. Chest 2001;119(6):1661-70.

185. Ram FS, Jardin JR, Atallah A, Castro AA, Mazzini R, Goldstein R, Lacasse Y, Cendon S. Efficacy of theophylline in people with stable chronic obstructive pulmonary disease: a systematic review and meta-analysis. Respir Med 2005;99(2):135-44.

186. Devereux G, Cotton S, Fielding S, McMeekin N, Barnes PJ, Briggs A Burns G, Chaudhuri R, Chrystyn H, Davies L, De Soyza A, Gompertz S, Haughney J, Innes K, Kaniewska J, Lee A, Morice A, Norrie J, Sullivan A, Wilson A, Price D. Effect of Theophylline as Adjunct to Inhaled Corticosteroids on Exacerbations in Patients With COPD: A Randomized Clinical Trial. JAMA 2018;320(15):1548-59.

187. van Geffen WH, Kerstjens HAM, Slebos DJ. Emerging bronchoscopic treatments for chronic obstructive pulmonary disease. Pharmacol Ther 2017;179:96-101.

188. Criner GJ, Sue R, Wright S, Dransfield M, Rivas-Perez $H$, Wiese $T$, Sciurba FC, Shah PL, Wahidi MM, de Oliveira HG, Morrissey B, Cardoso PFG, Hays S, Majid A, Pastis N Jr, Kopas L, Vollenweider M, McFadden PM, Machuzak M, Hsia DW, Sung A, Jarad N Kornaszewska M, Hazelrigg S, Krishna G, Armstrong B, Shargill NS, Slebos DJ; LIBERATE Study Group. A Multicenter Randomized Controlled Trial of Zephyr Endobronchial Valve Treatment in Heterogeneous Emphysema (LIBERATE). Am J Respir Crit Care Med 2018;198(9):1151-64.

189. Valipour A. Valve therapy in patients with emphysematous type of chronic obstructive pulmonary disease (COPD): from randomized trials to patient selection in clinical practice. J Thorac Dis 2018;10(Suppl 23):S2780-96.

190. Kemp SV, Slebos DJ, Kirk A, Kornaszewska M, Carron K, Ek L, Broman G, Hillerdal G, Mal H, Pison C, Briault A, Downer N, Darwiche K, Rao J, Hübner RH, Ruwwe-Glosenkamp C, Trosini-Desert V, Eberhardt R, Herth FJ, Derom E, Malfait T, Shah PL, Garner JL, Ten Hacken NH, Fallouh H, Leroy S, Marquette CH; TRANSFORM Study Team * . A Multicenter Randomized Controlled Trial of Zephyr Endobronchial Valve Treatment in Heterogeneous Emphysema (TRANSFORM). Am J Respir Crit Care Med 2017;196(12):1535-43.

191. Herth FJ, Slebos DJ, Rabe KF, Shah PL. Endoscopic Lung Volume Reduction: An Expert Panel Recommendation. Respiration 2016;91(3):241-50

192. Slebos DJ, Klooster K, Ten Hacken NHT. Bronchoscopic lung volume reduction. In: Herth FJF, Shah PL, Gompelmann D, editors. Interventional Pulmonology (ERS Monograph). Sheffield: European Respiratory Society; 2017. pp. 276-293.

193. Gülşen A. Bronchoscopic Lung Volume Reduction: A 2018 Review and Update. Turk Thorac J. 2018;19(3):141-49.

194. Decker MR, Leverson GE, Jaoude WA, Maloney JD. Lung volume reduction surgery since the National Emphysema Treatment Trial: study of Society of Thoracic Surgeons Database. J Thorac Cardiovasc Surg 2014;148(6):2651-8.e1.

195. Gordon M, Duffy S, Criner GJ. Lung volume reduction surgery or bronchoscopic lung volume reduction: is there an algorithm for allocation? JThorac Dis 2018;10(Suppl 23):S2816-S2823.

196. Shah PL, Herth FJ, van Geffen WH, Deslee G, Slebos DJ. Lung volume reduction for emphysema. Lancet Respir Med 2017;5(2):147-56.

197. Palla A, Desideri M, Rossi G, Bardi G, Mazzantini D, Mussi A, Giuntini C. Elective surgery for giant bullous emphysema: a 5-year clinical and functional follow-up. Chest 2005;128(4):2043-50.

198. Neviere R, Catto M, Bautin N, Robin S, Porte H, Desbordes J, Matran $\mathrm{R}$. Longitudinal changes in hyperinflation parameters and exercise capacity after giant bullous emphysema surgery. J Thorac Cardiovasc Surg 2006;132(5):1203-07.

199. Greenberg JA, Singhal S, Kaiser LR. Giant bullous lung disease: evaluation, selection, techniques, and outcomes. Chest Surg Clin N Am 2003;13(4):631-49.

200. Liu L, Wang JL, Xu XY, Feng M, Hou Y, Chen L. Leukotriene receptor antagonists do not improve lung function decline in COPD: a meta-analysis. Eur Rev Med Pharmacol Sci 2018;22(3):829-34.

201. Rubinstein I, Kumar B, Schriever C. Long-term montelukast therapy in moderate to severe COPD--a preliminary observation. Respir Med 2004;98(2):134-38.

202. Ricevuti G, Mazzone A, Uccelli E, Gazzani G, Fregnan GB. Influence of erdosteine, a mucolytic agent, on amoxycillin penetration into sputum in patients with an infective exacerbation of chronic bronchitis. Thorax 1988;43(8):585-90.

203. Polverino E, Goeminne PC, McDonnell MJ, Aliberti S, Marshall SE, Loebinger MR, Murris M, Cantón R, Torres A, Dimakou K, De Soyza A, Hill AT, Haworth CS, Vendrell M, Ringshausen FC, Subotic D, Wilson R, Vilaró J, Stallberg B, Welte T, Rohde G, Blasi F, Elborn S, Almagro 
M, Timothy A, Ruddy T, Tonia T, Rigau D, Chalmers JD. European Respiratory Society guidelines for the management of adult bronchiectasis. Eur Respir J 2017;50(3):1700629.

204. Boaventura R, Shoemark A, Chalmers JD. Pathophysiology. In: Chalmers JD, Polverino E, Aliberti S. Bronchiectasis. European Respiratory Monograph 2018. European Respiratory Society. 2018. p. 8-28.

205. Sidhu MK, Mandal P, Hill AT. Developing drug therapies in bronchiectasis. Expert Opin Investig Drugs 2015;24(2):169-81.

206. van Beers $M$, Rutten-van Mölken MPMH, van de Bool C, Boland $M$, Kremers SPJ, Franssen FME, van Helvoort A, Gosker HR, Wouters EF, Schols AMWJ. Clinical outcome and cost-effectiveness of a 1-year nutritional intervention programme in COPD patients with low muscle mass: The randomized controlled NUTRAIN trial. Clin Nutr 2020;39(2):405-13.

207. Ahmadi Z, Sundh J, Bornefalk-Hermansson A, Ekström M. LongTerm Oxygen Therapy 24 vs $15 \mathrm{~h}$ /day and Mortality in Chronic Obstructive Pulmonary Disease. PLoS One 2016;11(9):e0163293.

208. Górecka D, Gorzelak K, Sliwiński P, Tobiasz M, Zieliński J. Effect of long-term oxygen therapy on survival in patients with chronic obstructive pulmonary disease with moderate hypoxaemia. Thorax 1997;52(8):674-79.

209. Czech Pneumological and Phthisiological Society. Guidelines for indication of domiciliary long-term oxygen therapy. Updated 2016 [Cited 2020 Sept 24]. Available from: http://www.pneumologie.cz/ upload/1480163901.pdf (In Czech)

210. Dreher M, Storre JH, Schmoor C, Windisch W. High-intensity versus low-intensity non-invasive ventilation in patients with stable hypercapnic COPD: a randomised crossover trial. Thorax 2010;65(4):30308.

211. Liao H, Pei W, Li H, Luo Y, Wang K, Li R, Xu L, Chen X. Efficacy of long-term noninvasive positive pressure ventilation in stable hypercapnic COPD patients with respiratory failure: a meta-analysis of randomized controlled trials. Int J Chron Obstruct Pulmon Dis 2017;12:2977-85.

212. Windisch W, Haenel M, Storre JH, Dreher M. High-intensity noninvasive positive pressure ventilation for stable hypercapnic COPD. Int J Med Sci 2009;6(2):72-76.

213. Windisch W, Geiseler J, Simon K, Walterspacher S, Dreher M; on behalf of the Guideline Commission. German National Guideline for Treating Chronic Respiratory Failure with Invasive and NonInvasive Ventilation - Revised Edition 2017: Part 2. Respiration 2018;96(2):171-203

214. Du W, Liu J, Zhou J, Ye D, OuYang Y, Deng Q. Obstructive sleep apnea, COPD, the overlap syndrome, and mortality: results from the 2005-2008 National Health and Nutrition Examination Survey. Int J Chron Obstruct Pulmon Dis 2018;13:665-74.

215. Duiverman ML, Wempe JB, Bladder G, Jansen DF, Kerstjens HA Zijlstra JG, Wijkstra PJ. Nocturnal non-invasive ventilation in addition to rehabilitation in hypercapnic patients with COPD. Thorax 2008;63(12):1052-57.

216. Duiverman ML, Wempe JB, Bladder G, Vonk JM, Zijlstra JG, Kerstjens HA, Wijkstra PJ. Two-year home-based nocturnal noninvasive ventilation added to rehabilitation in chronic obstructive pulmonary disease patients: a randomized controlled trial. Respir Res 2011;12(1):112

217. Köhnlein T, Windisch W, Köhler D, Drabik A, Geiseler J, Hartl S, Karg O, Laier-Groeneveld G, Nava S, Schönhofer B, Schucher B, Wegscheider K, Criée CP, Welte T. Non-invasive positive pressure ventilation for the treatment of severe stable chronic obstructive pulmonary disease: a prospective, multicentre, randomised, controlled clinical trial. Lancet Respir Med 2014;2(9):698-705.

218. Struik FM, Sprooten RT, Kerstjens HA, Bladder G, Zijnen M, Asin J, Cobben NA, Vonk JM, Wijkstra PJ. Nocturnal non-invasive ventilation in COPD patients with prolonged hypercapnia after ventilatory support for acute respiratory failure: a randomised, controlled, parallel-group study. Thorax 2014;69(9):826-34.

219. Murphy PB, Rehal S, Arbane G, Bourke S, Calverley PMA, Crook AM, Dowson L, Duffy N, Gibson GJ, Hughes PD, Hurst JR, Lewis KE, Mukherjee R, Nickol A, Oscroft N, Patout M, Pepperell J, Smith I, Stradling JR, Wedzicha JA, Polkey MI, Elliott MW, Hart N. Effect of Home Noninvasive Ventilation With Oxygen Therapy vs Oxygen Therapy Alone on Hospital Readmission or Death After an Acute COPD Exacerbation: A Randomized Clinical Trial. JAMA 2017;317(21):2177-86.

220. ISHLT: The International Society for Health and Lung transplantation. Slide Sets - Adult Lung Transplantation Statistics. [Cited 2020 Oct 26]. Available from: https://ishltregistries.org/downloadables/ slides/2019/lung_adult.pptx

221. Czech Pneumological and Phthisiological Society. Guidelines for indication of lung transplantation. Updated 2019. [Cited 2020 Sept 24]. Available from: http://www.pneumologie.cz/upload/1575651910.5864.doc (In Czech)

222. Weill D. Lung transplantation: indications and contraindications. $J$ Thorac Dis 2018;10(7):4574-87.

223. Curtis JR. Palliative and end-of-life care for patients with severe COPD. Eur Respir J 2008;32(3):796-803

224. Carlucci A, Guerrieri A, Nava S. Palliative care in COPD patients: is it only an end-of-life issue? Eur Respir Rev 2012;21(126):347-54.

225. Lee AL, Goldstein RS. Gastroesophageal reflux disease in COPD: links and risks. Int J Chron Obstruct Pulmon Dis 2015;10:1935-49.

226. McNicholas WT. COPD-OSA Overlap Syndrome: Evolving Evidence Regarding Epidemiology, Clinical Consequences, and Management. Chest 2017;152(6):1318-26.

227. Miravitlles M, Roche N, Cardoso J, Halpin D, Aisanov Z, Kankaanranta H, Koblizek V, Sliwinski P, Bjermer L, Tamm M, Blasi F, Vogelmeier CF. Chronic obstructive pulmonary disease guidelines in Europe: a look into the future. Respir Res 2018;19(1):11.

228. Dal Negro RW, Bonadiman L, Turco P, Tognella S, lannazzo S. Costs of illness analysis in Italian patients with chronic obstructive pulmonary disease (COPD): an update. Clinicoecon Outcomes Res 2015;7:153-59.

229. US Preventive Services Task Force (USPSTF), Siu AL, BibbinsDomingo K, Grossman DC, Davidson KW, Epling JW Jr, García FA, Gillman M, Kemper AR, Krist AH, Kurth AE, Landefeld CS, Mangione CM, Harper DM, Phillips WR, Phipps MG, Pignone MP. Screening for Chronic Obstructive Pulmonary Disease: US Preventive Services Task Force Recommendation Statement. JAMA 2016;315(13):13727.

230. López Varela MV, Montes de Oca M, Rey A, Casas A, Stirbulov R, Di Boscio V; PUMA Team. Development of a simple screening tool for opportunistic COPD case finding in primary care in Latin America: The PUMA study. Respirology 2016;21(7):1227-34.

231. Çolak Y, Afzal S, Nordestgaard BG, Vestbo J, Lange P. Prognosis of asymptomatic and symptomatic, undiagnosed COPD in the general population in Denmark: a prospective cohort study. Lancet Respir Med 2017;5(5):426-34.

232. Capozzolo A, Castellana G, Dragonieri S, Carratù P, Liotino V, Vulp MR, Marra L, Resta E, Intiglietta P, Resta O. Voluntary lung function screening to reveal new COPD cases in southern Italy. Int J Chron Obstruct Pulmon Dis 2017;12:2035-42.

233. Jordan RE, Adab P, Sitch $A$, Enocson $A$, Blissett $D$, Jowett $S$, Marsh J, Riley RD, Miller MR, Cooper BG, Turner AM, Jolly K, Ayres JG, Haroon S, Stockley R, Greenfield S, Siebert S, Daley AJ, Cheng KK, Fitzmaurice D. Targeted case finding for chronic obstructive pulmonary disease versus routine practice in primary care (TargetCOPD): a cluster-randomised controlled trial. Lancet Respir Med 2016;4(9):720-30

234. Hemmingsen UB, Stycke M, Dollerup J, Poulsen PB. GuidelineBased Early Detection of Chronic Obstructive Pulmonary Disease in Eight Danish Municipalities: The TOP-KOM Study. Pulm Med 2017;2017:7620397.

235. Koblizek V, Hejduk K. A targeted search for patients with chronic obstructive pulmonary disease: brief summary. Vnitr Lek 2018;63(11):750-56. (In Czech)

236. Wouters EFM, Wouters BBREF, Augustin IML, Houben-Wilke $S$, Vanfleteren LEGW, Franssen FME. Personalised pulmonary rehabilitation in COPD. Eur Respir Rev 2018;27(147):170125.

237. Stockley RA, Halpin DMG, Celli BR, Singh D. Chronic Obstructive Pulmonary Disease Biomarkers and Their Interpretation. Am J Respir Crit Care Med 2019;199(10):1195-1204.

238. Mercado N, Ito K, Barnes PJ. Accelerated ageing of the lung in COPD: new concepts. Thorax 2015;70(5):482-9.

239. Barnes PJ. Targeting cytokines to treat asthma and chronic obstructive pulmonary disease. Nat Rev Immunol 2018;18(7):454-66.

240. Singh D, Martinez FJ, Watz H, Bengtsson T, Maurer BT. A dose-rang- 
ing study of the inhaled dual phosphodiesterase 3 and 4 inhibitor ensifentrine in COPD. Respir Res 2020;21(1):47.

241. Singh D, Emirova A, Francisco C, Santoro D, Govoni M, Nandeuil MA. Efficacy and safety of CHF6001, a novel inhaled PDE4 inhibitor in COPD: the PIONEER study. Respir Res. 2020 Sep 22;21(1):246.

242. Singh $D$, Fuhr $R$, Jimenez L, Wählby Hamrén U, Jauhiainen $A$, Malice MP, Balaguer V, Lei A, Aggarwal A, Astbury C, Psallidas I. A Randomized Trial of Dual-Acting Bronchodilator AZD8871 for Chronic Obstructive Pulmonary Disease. Am J Respir Crit Care Med 2019:199(10):1282-84.

243. Gross NJ, Barnes PJ. New Therapies for Asthma and Chronic Obstructive Pulmonary Disease. Am J Respir Crit Care Med 2017;195(2):159-66

244. Criner GJ, Celli BR, Singh D, Agusti A, Papi A, Jison M, Makulova N Shih VH, Brooks L, Barker P, Martin UJ, Newbold P. Predicting response to benralizumab in chronic obstructive pulmonary disease: analyses of GALATHEA and TERRANOVA studies. Lancet Respir Med 2020;8(2):158-170.

245. Halpin DM, Kerkhof M, Soriano JB, Mikkelsen H, Price DB. Eligibility of real-life patients with COPD for inclusion in trials of inhaled longacting bronchodilator therapy. Respir Res 2016;17(1):120.
246. Valipour A, Shah PL, Pison C, Ninane V, Janssens W, Perez T, Kessler R, Deslee G, Garner J, Abele C, Hartman JE, Slebos DJ; On behalf of the AIRFLOW-1 Study Group. Safety and Dose Study of Targeted Lung Denervation in Moderate/Severe COPD Patients. Respiration 2019;98(4):329-39.

247. Slebos DJ, Shah PL, Herth F, Pison C, Schumann C, Hübner RH, Bonta PI, Kessler R, Gesierich W, Darwiche K, Lamprecht B, Perez T, Skowasch D, Deslee G, Marceau A, Sciurba FC, Gosens R, Hartman JE, Srikanthan K, Duller M, Valipour A; AIRFLOW-2 Trial Study Group. Safety and Adverse Events after Targeted Lung Denervation for Symptomatic Moderate to Severe COPD (AIRFLOW): A Multicenter Randomized Controlled Trial. Am J Respir Crit Care Med 2019;200(12):1477-86.

248. Vanfleteren LE, Spruit MA, Groenen M, Gaffron S, van Empel VP, Bruijnzeel PL, Rutten EP, Op 't Roodt J, Wouters EF, Franssen FM. Clusters of comorbidities based on validated objective measurements and systemic inflammation in patients with chronic obstructive pulmonary disease. Am J Respir Crit Care Med 2013;187(7):728-35. 